\title{
A New, Ecologically Self-Significant Metric of Species-Abundance Unevenness, Reliably Highlighting the Intensity of Interspecific Competition
}

\author{
Jean Béguinot ${ }^{1^{*}}$ \\ ${ }^{1}$ Université de Bourgogne, 6, Boulevard Gabriel, 21000 Dijon, France.
}

Author's contribution

The sole author designed, analyzed, interpreted and prepared the manuscript.

Article Information

DOI: $10.9734 / A R R B / 2021 / v 36 i 430363$

Editor(s):

(1) Dr. Md. Torequl Islam, Federal University of Piaui, Brazil.

Reviewers:

(1) Wondimagegnehu Tekalign, Wolaita Sodo University, Ethiopia.

(2) Mohamed I. Marie, Helwan University, Egypt.

(3) Awé Djongmo Victor, University of Ngaoundere, Cameroon. Complete Peer review History: http://www.sdiarticle4.com/review-history/67322

Method Article

Received 12 February 2021 Accepted 21 April 2021 Published 27 April 2021

\begin{abstract}
A wide series of commonly used metrics of abundance-evenness (or -unevenness) have been proposed to characterize synthetically the distributions of species-abundances, accounting for the hierarchic-like organization of species within natural communities. Among them, most - if not allhave been relevantly criticized on their serious limitations regarding both their "descriptive" and their "interpretative" capacities. From the descriptive point of view, many authors have already repeatedly emphasized the formal non-independence of conventional (un-)evenness metrics with respect to species-richness, leading, in particular, to unacceptable bias when comparing communities differing by their species-richness, thus making these metrics unreliable descriptors in this respect. Now, as regards the capacity to provide relevant ecological interpretations, especially in terms of the intensity of competition among co-occurring species, the weakness of conventional (un-)evenness metrics is readily highlighted by the usual absence of any associated interpretation of this kind in the literature: the conventional (un-)evenness metrics being restricted to purely descriptive purpose only.

Accordingly, a newly designed abundance-unevenness metric - the "standardized abundanceunevenness" index is proposed, positively addressing both kinds of limitations evoked above. By
\end{abstract}


standardizing a conventional measure, $\mathrm{U}$, of abundance-unevenness to the corresponding measure, $U$ ', of the abundance-unevenness in the well-known "broken-stick" model, the resulting "standardized unevenness" index ( $I_{s t r}=U / U$ ') proves to be efficient against both the major limitations pointed-out above: indeed, the new index does benefit by being both (i) formally independent from species-richness, thereby allowing reliable, unbiased comparisons of abundance unevenness between species-communities, whatever their difference in species-richness; (ii) able to relevantly quantify the mean intensity of interspecific-competition within community, in term of its direct outcome upon the degree of species-abundance unevenness. This double success being, of course, the direct consequences of the properties of the "broken-stick" distribution model, originally put forth in a well-known, yet insufficiently thoroughly exploited paper by the regretted Robert MACARTHUR.

Keywords: Species-abundance; evenness; niche-diversification; niche-overlap; standardized unevenness index.

\section{INTRODUCTION}

The total number of co-occurring species within a natural community, and how vital resources of all kinds are partitioned among these species, both play a major role in the hierarchized organization of species abundances. Thereby making these two notions central to community ecology $[1,2]$. In practice, the hierarchized organization of species abundances is classically accounted for by the so-called Species Abundance Distribution ("S.A.D."). In turn, the "S.A.D." itself can conveniently be further synthesized, in terms of its two major features: the total species-richness and the degree of unevenness of the distribution of species abundances.

Now, although the total species-richness and the species-abundance unevenness seem, at first sight, being simple notions, with straightforwardly unambiguous meanings, both notions (including species-richness!) face, in fact, very tricky issues: on a practical ground as regards the species-richness and on a more conceptual ground regarding the species-abundance unevenness, as will be detailed hereafter.

* As concerns species-richness, the practical issue is to get a reliable access to the true - i.e. the total - species richness of the studied community. This can turn out to be very problematic in practice, as soon as speciose communities are dealt with, that include a significant part of rare, hard to record species. And this situation of practically unavoidable sampling incompleteness is becoming increasingly common, in particular with the generalization of the so-called "rapid biodiversity assessments", especially in tropical terrestrial or marine ecosystems $[3,4]$. Thus, quoting KERY \& ROYLE [3]: "virtually always, species richness cannot be observed but needs to be estimated because some species may be present but remain undetected. This fact is commonly ignored in ecology and management, although it will bias estimates of species richness and related parameters".

However, an alternative to impractical exhaustive samplings is now made available, in terms of achieving fairly reliable "least-biased" numerical extrapolation of such incomplete samplings. So that the practical issue with species-richness is now in process of being satisfactorily solved. Accordingly, this topic will only be briefly covered in some more detail in the next section.

* As regards, now, the species-abundance unevenness, the associated, more conceptual issue is to carefully define this notion, in order to ensure both (i) its reliability in term of descriptive representativeness and (ii) its relevance as an ecologically self-significant parameter. Here, the problem with conventionally used (un-) evenness indices arises from their lack of required formal independence from species-richness, as already repeatedly underlined by many authors: see [518]. In turn, this lack of formal independence makes these conventionally-defined indices unable to comply with the requirement of descriptive representativeness, as already strongly emphasized in [10]. And this, precisely, because the comparison of abundance (un-) evenness values between communities that substantially differ in their species-richness is severely biased, as a direct consequence of this formal dependence of conventional (un-) evenness upon species-richness.

And, for the same reason, relevant ecological interpretation of species-abundance unevenness cannot be derived when using conventional (un-) evenness indices, as will be more thoroughly detailed hereafter. 
It is, therefore, the main object of the present work to address both issues highlighted above, aiming at providing appropriate answers by defining a new type of abundance unevenness index - complementing conventional indices and satisfying both a reliable descriptive representativeness and a relevant ecological self-significance, as understood above.

\section{NUMERICAL EXTRAPOLATIONS OF BOTH (i) THE NUMBER OF UNRECORDED SPECIES AND (ii) THE RESPECTIVE ABUNDANCES OF EACH OF THEM}

For a long time, the numerical extrapolation of incomplete samplings has been restricted to the estimation of the number of unrecorded species by arbitrarily choosing one among a set of nonparametric estimators, among which the series of "Jackknife" and the "Chao" estimators were the more often implemented. This procedure yet remained rather unreliable and inaccurate as the different estimators, being quite differently expressed, often lead to substantially different estimates for, yet, a same community! As underlined by BROSE et al. in their seminal paper [19], it is - in principle - possible to gain in accuracy by non-arbitrarily choosing, in each case, which one, among the available estimators, would be the least-biased. Further improvement of the rational basis of selection of the leastbiased type of estimator was subsequently derived, based on the theoretical establishment of a rigorous relationship constraining the kinetics of species discovery along progressive sampling [20-25]. This has resulted in being able to propose a fully rational procedure of selection, of the best (i.e. least biased) estimator of the number of unrecorded species in each practical case. Finally, deriving least-biased estimate of the total species-richness [22,23]. Moreover, it revealed possible to reach the ultimate purpose of estimating the respective abundances of each of the unrecorded species and, thereby, to numerically extrapolate the complete Species Abundance Distribution, while yet disposing only from incomplete sampling [26]. Concrete examples of applications of these procedures are provided in the references proposed in Fig. 1.

Thus, taking a reliable account of the set of those rarer species (remained unrecorded but having their respective abundances numerically restored) is all the more important that such rare species - beyond their own intrinsic interest can disproportionately contribute to the functional structuring of communities, as already repeatedly emphasized [27-37]. As stated in [37]: "rare species are critical for bio-assessment".

In practice, ignoring the set of more or less rare species that remained unrecorded would inevitably lead to biased inferences [38].

\section{INTRODUCING A NEW METRIC OF SPECIES ABUNDANCE UNEVENNESS: THE "STANDARDIZED SPECIES- ABUNDANCE UNEVENNESS"}

\subsection{Preliminary: Defining the "Crude" Unevenness of Species-Abundance Distribution}

As mentioned in the Introduction, besides total species richness ' $\mathrm{S} t$ ', it is the degree ' $\mathrm{U}$ ' of unevenness of the distribution of species abundances that synthetically characterizes the hierarchic organization of species within natural communities.

Although habit has been taken to evoke abundance evenness, rather than abundance unevenness, it is the latter which, logically, should be preferred to properly address the degree of hierarchic structuring of species abundances within natural communities, following in that references $[39,40]$. And, in compliance with the usual mode of representation of Species Abundance Distributions, it goes natural to quantify the degree of "crude" abundance unevenness " $U$ " as the average slope of the log-transformed abundance decrease, as already proposed in [41], that is:

$$
\begin{aligned}
& U=\left[\log _{10}\left(\mathrm{a}_{1}\right)-\log _{10}\left(\mathrm{ast}_{\mathrm{St}}\right)\right] /\left(\mathrm{S}_{\mathrm{t}}-1\right) \\
& \mathrm{U}=\left[\log _{10}\left(\mathrm{a}_{1} / \mathrm{ast}_{\mathrm{st}}\right)\right] /\left(\mathrm{S}_{\mathrm{t}}-1\right)
\end{aligned}
$$

with $a_{1}$ and ast standing for the highest and the lowest relative abundances in the studied community (relative abundances: $\Sigma a_{i}=1$ ).

Note that choosing this mode of definition of abundance-unevenness preserves the symmetric consideration of minor and abundant species and thus, the equitable account of every co-occurring species, independently of their respective abundances - which is admittedly desirable [10]. Contrasting in that with many commonly used metrics of (un-) evenness which - conventionally and rather arbitrarily - attribute different weights to co-occurring species, according to their commonness or rarity [10]. 


\subsection{Standardizing Species-Abundance Unevenness to Derive a Relevantly "Descriptive" Metric, Allowing Unbiased Comparisons Whatever the Difference in Species-Richness}

From a descriptive point of view, the "crude" abundance-unevenness $U$ has the major inconvenience of being partly dependent upon species richness, as already emphasized by numerous authors for most, if not all, the conventionally designed (un-) evenness metrics [5-18].

Further, based on an extensive survey of 38 marine communities (involving either fish or various groups of invertebrates), Fig. 1 provides an illustration - and a further ample additional empirical confirmation - of this trend for a (negative) dependence of crude speciesabundance unevenness upon species-richness [incidentally, it is worth noting that the dependence of the crude unevenness $U$ upon species-richness is mainly due to the corresponding variation of the lowest speciesabundance ast with species-richness since the corresponding variation of the highest speciesabundance $a_{1}$ remains comparatively quite weak: see Appendix 1 for argumentation].
The formal (negative) linkage to species-richness of the conventional (un-) evenness indices (among which the defined-above crude abundance-unevenness $U$ ) makes all these conventional metrics quite inappropriate (a potentially severe source of bias), when comparing communities differing in species richness, as already said, and especially claimed, for example, by SMITH \& WILSON [10]: "to make sense, (un)evenness must be independent of species richness".

It would, thus, feature relevant to consider, besides the crude unevenness itself, a standardized unevenness metric, "Istr", defined by rationalizing the crude unevenness $U$ to a curve accounting for this overall trend of decrease of crude unevenness with species richness. Thereby making this standardized unevenness metric mathematically independent of this trend (once more, as required by many authors and SMITH \& WILSON [10] in particular).

Various possibilities arise to define this referential curve, intended to serve as the standardization basis for this new unevenness metric: for example, the regression of the variations of crude unevenness $U$ with species richness St, shown in Fig. 1.

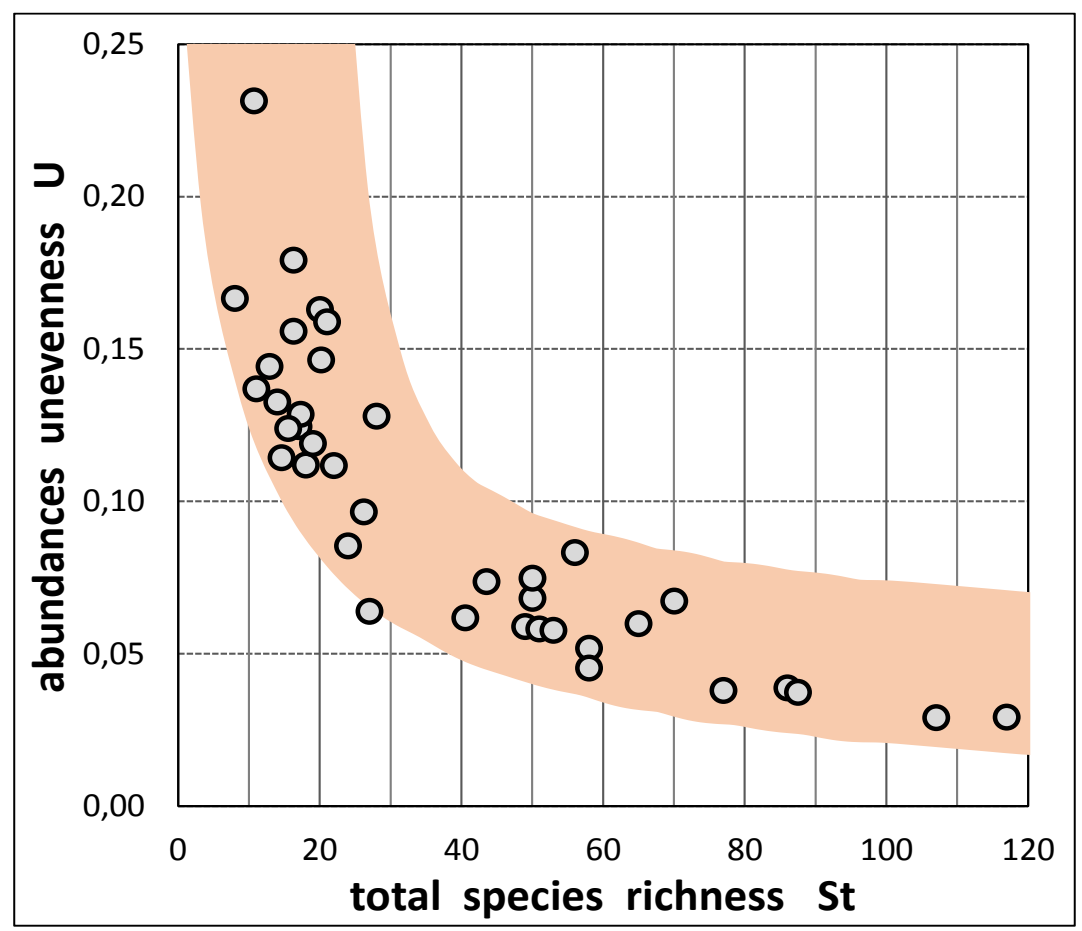

Fig. 1. Crude species abundance unevenness "U" plotted against total species richness $S_{t}$ for 38 marine communities (derived from references [42-52] ) 
Yet, another, more appropriate and - as will be seen - far more interesting possibility, arises alternatively. Namely, by referring to the unevenness, U', of the well-known "broken-stick" distribution, originally proposed by MACARTHUR [53]. Since it turns out that the overall trend of negative dependence of crude unevenness upon species richness, highlighted in Fig. 1, is remarkably paralleled by the decrease of the "broken-stick" unevenness U' with respect to species-richness, as highlighted in Fig. 2. More precisely, the broken-stick unevenness adequately positions itself as a fair base-line for the empirical distribution of the crude abundance unevenness values plotted against speciesrichness (Fig. 2). In fact, this parallelism is not surprising - and could even have been expected - given that the "broken-stick" distribution (and, in particular its abundance unevenness) disposes of the unique property of being both solely and univocally dependent upon speciesrichness [9,53,54], see also Appendix 2). This univocal dependence upon $S_{t}$ being more explicitly emphasized when literally writing $U$ ' as "U'(St)".

The broken-stick unevenness, U' $\left(=U^{\prime}\left(S_{t}\right)\right)$, thus being especially adequate to take reliable account of the influential trend of dependence of the crude unevenness $U$ upon species-richness.
Accordingly, for descriptive purposes (aiming in particular to allow unbiased comparisons of species-abundances unevenness among communities whatever their difference in species-richness), it is therefore appropriate to define a "standardized" expression of speciesabundance unevenness, as the ratio, $U / U^{\prime}\left(S_{t}\right)$, between the crude unevenness $U$ and the unevenness ' $U$ ' of the broken-stick distribution.

The "standardized unevenness index "Istr" (equal to $U / U$ ') is thus defined as:

$\mathrm{I}_{\text {str }}=\left[\log _{10}\left(\mathrm{a}_{1} / \mathrm{ast}_{\mathrm{St}}\right) /\left(\mathrm{S}_{\mathrm{t}}-1\right)\right] /\left[\log _{10}\left(\mathrm{a}^{\prime}{ }_{1} / \mathrm{a}^{\prime} \mathrm{st}_{\mathrm{t}}\right) /\left(\mathrm{S}_{\mathrm{t}}-1\right)\right]$

that is:

$I_{s t r}=U / U^{\prime}=\log _{10}\left(a_{1} / a_{s t}\right) / \log _{10}\left(a^{\prime}{ }_{1} / a^{\prime}{ }^{\prime} t\right)$

with $\mathrm{a}_{1}$ and ast standing for the highest and the lowest relative abundances in the studied community and $a^{\prime}{ }_{1}$ and a'st standing for the highest and the lowest relative abundances in the corresponding "broken-stick" distribution for the same species richness $S_{t}$. The distribution of the relative abundances $\left(a^{\prime} i\right)$ for the broken-stick distribution and the corresponding abundance unevenness $U^{\prime}(\mathrm{St})$ being easily computed according to references $[9,53,54]$, with practical indications also given in Appendix 2.

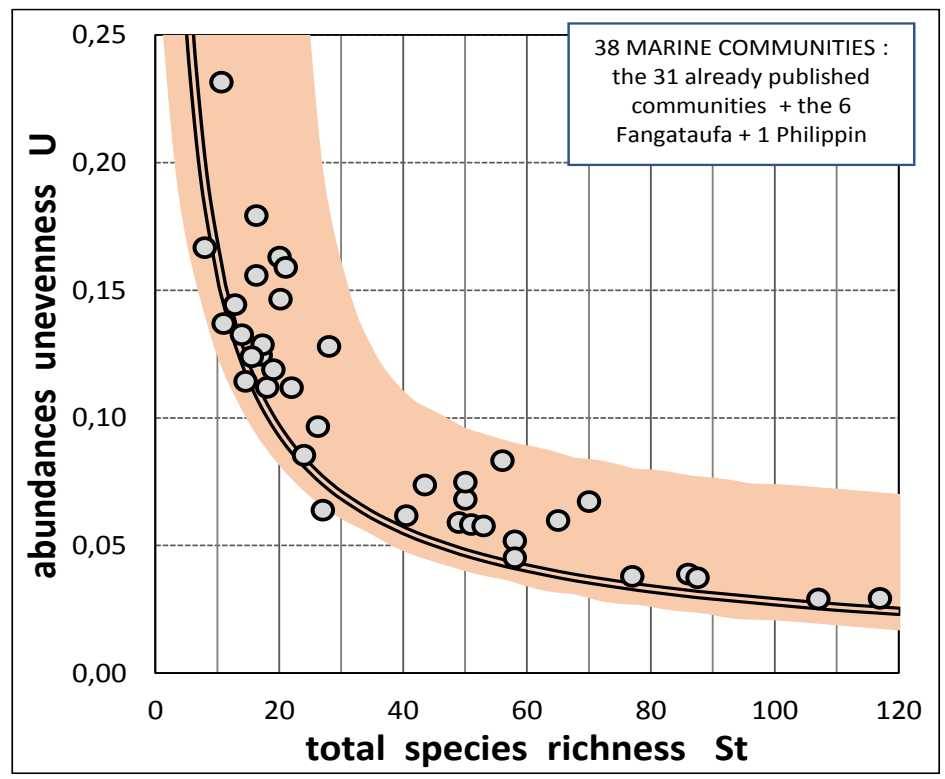

Fig. 2. Crude species-abundance unevenness $U$ (grey discs) plotted against total speciesrichness $S_{t}$ for 38 marine communities (after [42-52]). The overall trend for a negative linkage between the crude unevenness $U$ and the total species-richness $S_{t}$ is remarkably paralleled by the decrease of the broken-stick unevenness, U', with respect to species-richness (doubleline). More precisely, the broken-stick unevenness $U$ ' adequately positions itself as a fair baseline for the overall distribution of the crude abundance unevenness $\mathrm{U}$. 
Thus defined, the "standardized" abundance unevenness, $I_{s t r}=U / U$ ', relevantly complies with the formal independence from species richness, required for making reliable comparisons between communities, whatever their difference in species richness.

Moreover, as will be shown below, selecting the "broken-stick" distribution as the referential standard for unevenness will - also - reveal especially relevant in the perspective of deriving an ecologically self-significant metric for speciesabundance unevenness.

\subsection{Standardizing Species Abundance Unevenness to Derive an "Ecologically Self-Significant" Metric}

An overall trend exists, for increasing speciesrichness being accommodated by improved niche diversification. Thereby allowing better resource-partitioning among co-occurring species and limiting, or even avoiding, the risk for an increasing proportion of niche-overlaps, as a consequence of growing species-richness - and thus, the potential onset of interspecific contest for shared resource at niche-overlaps, triggered when sufficient density in individuals is reached among competing species [55-58].

Now, admittedly, it is not so frequent to encounter, in nature, an "ideal" accommodation of species richness, that is the accommodation of an increasing number of species while avoiding the onset of niche-overlaps (or, at least, avoiding that niche-overlaps become "functional' due to the density of individuals reaching sufficient level to trigger significant interspecific contest for shared resource at these overlaps [55,57]). In other words (referring to the notions developed by MACARTHUR [53]), the "ideal" situation of "contiguous non-overlapping niches" pattern (avoiding interspecific contest for shared resource) is not so commonly achieved. Even if this "ideal" situation proves being more frequent, or even usual, within some particular groups of "higher" taxa, such as birds or mammals possibly resulting from their capacity to improve the auto-regulation of their densities in individuals, thereby depressing or even canceling the functionality of possibly existing nicheoverlaps.

So that, except for such particular cases, the common rule is for various degrees of interspecific-competition to occur (and even to more or less lengthily maintain) within natural communities, at almost any level of species- richness (as exemplified further at Fig. $9 \& 10$ ). And this, despite the reduction of interspecificcompetition is generally considered as being selectively positive and, thus, an "attractive" trend, indeed supported by some pieces of empirical data (as highlighted further below).

In short, more or less lengthy interspecific contests for shared resources of any kind (food, space, protection,...) between co-occurring species is obviously the common, or at least transient situation observed in nature [58,59].

Thus, the "attractive" situation of a "continuous, non-overlapping" display of occupied niches, defined by MACARTHUR[53] as ideally avoiding interspecific-competition, correspond precisely to this particular abundance distribution - the "broken-stick" - already shown above as being efficient to provide a reliable descriptive capacity to the standardized unevenness index $I_{\text {str. }}$.

With, moreover, still the same "broken-stick" distribution providing also - and surely not coincidentally - a fair base-line for the empirical distribution of the "crude" abundance unevenness $U$ according to species-richness (Fig. 2). All that make the "broken-stick" distribution an obvious "focal-pole" for community ecology, well beyond what was generally considered, or admitted, up to now!

Now, coming back to the goal of deriving relevant ecological interpretations from abundanceunevenness data, the crude abundanceunevenness $U$, as such, also reveals inappropriate in this last respect - and this precisely for the same reason which makes the crude abundance unevenness already inappropriate for reliable descriptiveness: the overall trend for the (negative) dependence of crude abundance-unevenness $U$ upon speciesrichness, see references [5-18] and Fig.1.

Accordingly, here also, it is the standardization of the crude unevenness $U$ to the unevenness $U^{\prime}\left(S_{t}\right)$ of the "broken-stick" distribution which will allow the standardized unevenness index $I_{\text {str }}$ to provide relevant ecological interpretations. By adequately disentangling and separating what, in crude unevenness $U$, actually results from the intensity of interspecific-competition from what simply depends directly upon species-richness.

So that, the standardized unevenness index "Istr", defined at first to ensure reliable descriptive representativeness, proves now being adequate, as well, to relevantly mirror the mean intensity of interspecific-competition resulting from the 
interspecific contests (if any) at functional nicheoverlaps.

In compliance with that, Figs. 3 and 4 provide a schematic representation of the conception of MACARTHUR, in term of the linkage between (i) the crude unevenness $U$ of species abundances (at any given level of species richness) and (ii) the corresponding ecological background, that is, the pattern of niches display, intended to drive the existence and the intensity of interspecificcompetition.

Thus - and once more not coincidentally - it is one and the same index which reveals able to appropriately account for both the descriptive and the ecological points of view. With the "broken-stick" distribution, originally promoted by MACARTHUR, being the common focal node involved in each of these two perspectives.

To summarize, for practical use, the ecological interpretation attached to the standardized unevenness 'Istr' values:

${ }^{*} I_{\text {str }}=1$ : the niches are contiguous but, yet, without overlaps among them (at least functionally speaking): thus, no competitive interaction (no interspecific-contest) actually occurs, which would enhance the unevenness of species abundances beyond what results from the disparity between niches respective rewards to their respectively associated species [60-63]. Disparity of rewards which is modeled, in an aptly stochastic manner, by the broken-stick distribution, as argued in [53].

${ }^{*} I_{\text {str }}>1$ : the niches are partially overlapping (not only geometrically but also functionally according to the density of individuals mutually contesting for shared resource at nicheoverlaps), thereby inducing competitive interactions between co-occurring species competitive interactions all the more intense than Istr exceeds unity;

${ }^{*} I_{\text {str }}<1$ : the niches are said to be "separate" [53], which means, in practice, that only part of them are actually occupied - with those preferentially occupied niches being expectedly the more (or, less likely, the less) rewarding to their respectively associated species. In either alternatives, the occupied niches are more similar among them than the average, in terms of the respective rewards provided to their respectively associated species. Accordingly, in such cases, the level of abundance unevenness is lower than in the case of contiguous nonoverlapping niche, due to the preferential occupancy of more similarly rewarding niches. And all the lower than $I_{\text {str }}$ falls more below unity.

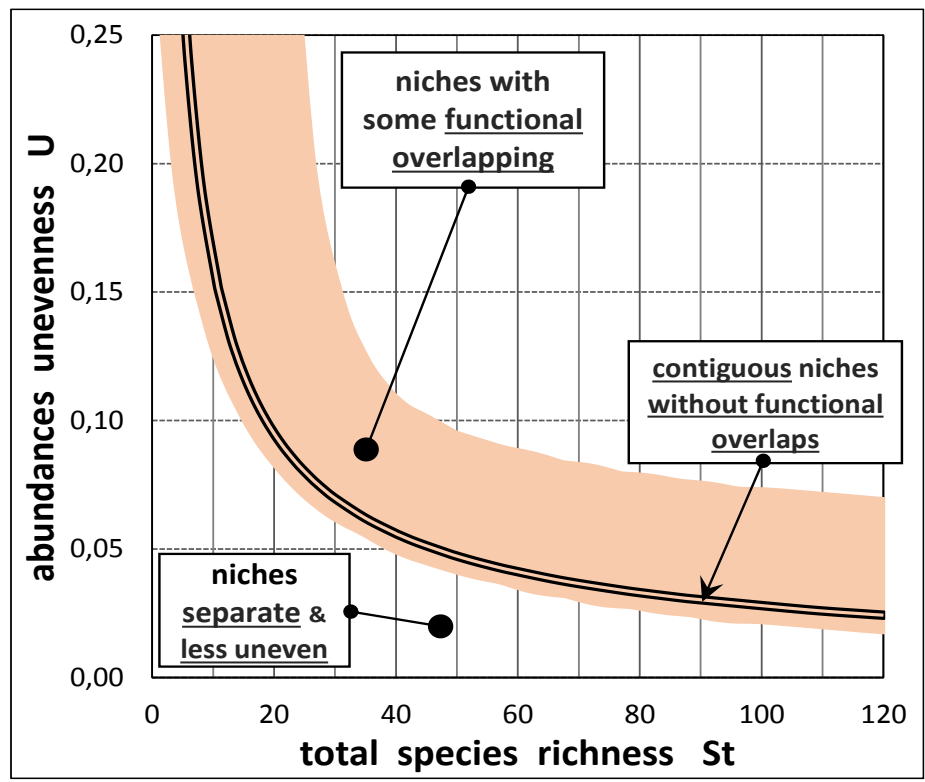

Fig. 3. The schematic ecological interpretation to be given to the "crude" species-abundance unevenness, $U$, in terms of the different patterns of niches display, by reference to the conception of MacArthur [53]. The "broken-stick" distribution (double-line) denoting the "contiguous, non-overlapping niche" pattern - the latter separating: (i) the "separate niches" pattern for $U<U^{\prime}\left(S_{t}\right)$ and (ii) the "functionally overlapping niches" pattern for $U>U^{\prime}\left(S_{t}\right)$ 


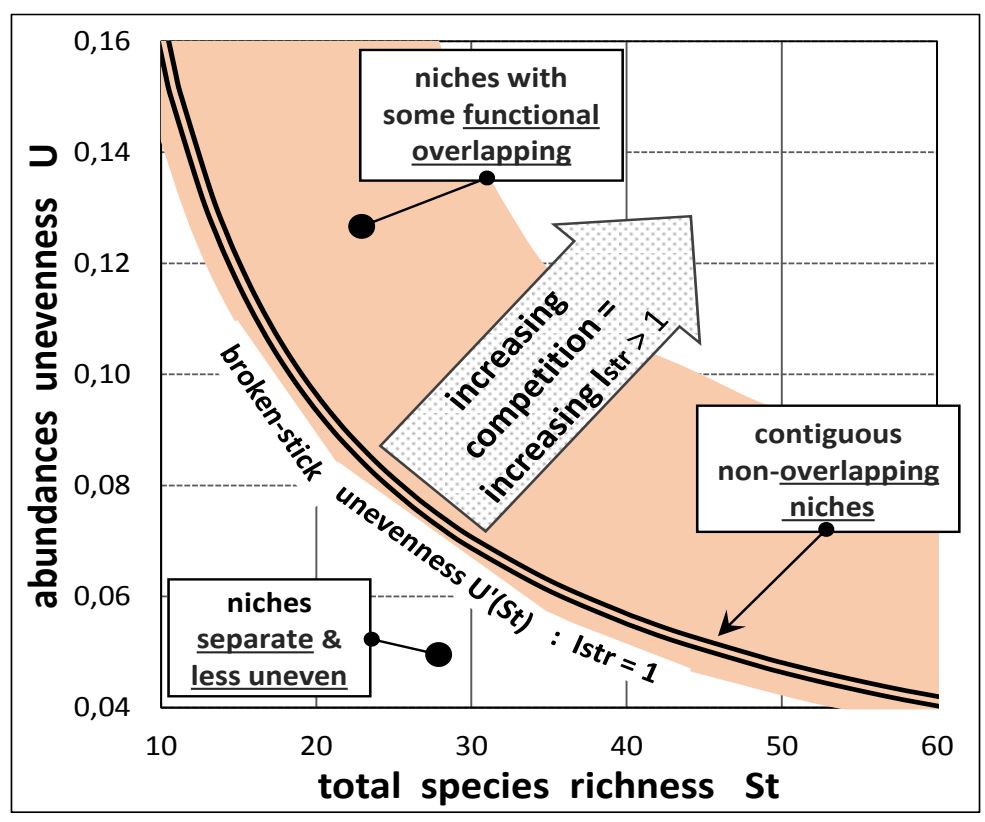

Fig. 4. Same as Fig. 3, slightly magnified to include the corresponding functional interpretation, in terms of the interspecific-competition intensity - aptly mirrored by the “standardized unevenness index" $\mathrm{I}_{\mathrm{str}}=\mathrm{U} / \mathrm{U}$ ' $\left(\mathrm{S}_{\mathrm{t}}\right)$, complying with MACARTHUR conception [53]

\begin{tabular}{|c|c|c|}
\hline $\begin{array}{l}\text { CONTRIBUTORS to } \\
\text { ABUNDANCE } \rightarrow \\
\text { UNEVENNESS }\end{array}$ & $\begin{array}{l}\text { * uneven niche rewards } \\
\text { to their respectively } \\
\text { associated species }\end{array}$ & $\begin{array}{l}\text { * interspecific contest } \\
\text { for shared resource } \\
\text { at niches overlaps }\end{array}$ \\
\hline$I_{s t r}$ & $\begin{array}{l}\text { only partial occupancy of available niches and } \\
\text { preferentially those niches providing more similar } \\
\text { rewards to their respectively associated species } \\
\rightarrow \text { hence, low levels of abundance unevenness } \\
\text { and this all the more than } I_{\text {str }} \text { is less than } 1\end{array}$ & $\begin{array}{l}\text { no interspecific contest } \\
\text { (no niche functional overlap, } \\
\text { since niches are separate) }\end{array}$ \\
\hline$I_{s t r}=$ & $\begin{array}{l}\text { full occupancy of available niches } \\
\text { (i.e. "contiguous" non-overlapping niches) } \\
\rightarrow \text { hence, rewards of niches to their associated } \\
\text { species are more uneven than they were above, } \\
\text { thus leading to more uneven distribution of } \\
\text { species abundances than above }: \mathrm{I}_{\text {str }}=1\end{array}$ & $\begin{array}{l}\text { still no interspecific contest, } \\
\text { since niches, being contiguous, } \\
\text { there are still no functional- } \\
\text { overlap between niches }\end{array}$ \\
\hline 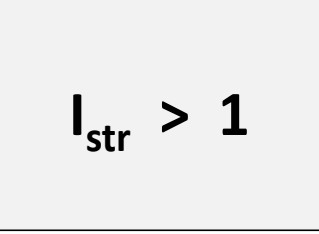 & $\begin{array}{l}\text { full occupancy of available niches } \\
\text { (now partially intersecting) } \\
\rightarrow \text { hence, the same contribution, as above, to } \\
\text { the uneven distribution of species abundances, } \\
\text { but see now the new contrib. of intersp. contest }\end{array}$ & $\begin{array}{l}\text { interspecific contests } \\
\text { now adding supplementary } \\
\text { abundance unevenness } \\
\text { and all the more than } \mathrm{I}_{\text {str }}>1 \\
\text { (answering the increase in } \\
\text { functional-overlaps) }\end{array}$ \\
\hline
\end{tabular}

Fig. 5. A summarized guidance to the ecological interpretation attached to various range of values taken by the "standardized abundance-unevenness index" $I_{\text {str }}$

\subsubsection{Important practical notice}

Although the standardization has been applied, above, to the specific definition of crude unevenness $U$ given in equation (1), the benefits inherent to this standardization procedure can be freely extended to any other definition that would be chosen for the crude abundance-unevenness index and - even - mutatis mutandis, to any definition of crude abundance evenness, among the numerous metrics proposed in the literature. Being understood that in the latter case, i.e. when it is evenness (instead of unevenness) which is considered, it would be (of course) Istr 
values lesser than unity (instead of higher) which would mirror the intensity of interspecificcompetition.

\subsection{Quantifying the Mean Intensity of Inter Specific Competition within Community}

Interspecific competition is a process: as such its relevant quantification is not intrinsic but appropriately expressed in terms of its direct outcome, namely the resulting increase in species-abundance unevenness, characterized by the steepness of the slope of the species abundance distribution. Thus, the mean intensity of interspecific competition is reliably quantified by the resulting increase of species-abundance unevenness. And it has been shown above that it is precisely the standardized unevenness index Istr which measures by how much the speciesabundance unevenness is multiplied, as the consequence of interspecific competition. This is explicitly highlighted by the following equation immediately derived from the expression (2) of Istr:

$$
\mathrm{U}=\left[\mathrm{U}^{\prime}\left(\mathrm{S}_{\mathrm{t}}\right)\right] \cdot\left[\mathrm{lstr}_{\mathrm{str}}\right]
$$

where U'( $\left.\mathrm{S}_{\mathrm{t}}\right)$ (the corresponding "broken-stick" unevenness) stands for what would be the unevenness level in the absence of interspecificcompetition for shared resource at nicheoverlaps.

Thus, the "standardized abundance unevenness" Istr not only simply "mirrors" the interspecific competition. It actually relevantly quantifies the mean intensity of interspecific-competition within community, expressed in the appropriate term of its straightforwardly measurable outcome: namely, its contribution to the uneven distribution of species-abundances, as a multiplicative factor applying to what would be the abundanceunevenness $\left(=U^{\prime}\right)$ in the absence of competition.

Equation (3) thus highlights also the essentially "composite" nature of crude species-abundance unevenness - regrettably ignored in conventional metrics of (un-)evenness. A composite nature which combines multiplicatively:

(i) the contribution U' (i.e. the broken-stick unevenness) that would stand in the ideal absence of interspecific-competition at niche-overlaps and is, thus, uniquely related to the degree of ideal nichediversification, allowing in turn the accommodation of the realized speciesrichness $\mathrm{S}_{\mathrm{t}}$ (the reason why $U$ ' is a univocal function $U^{\prime}\left(S_{t}\right)$ of species-richness);

(ii) the contribution $\mathbf{I}_{\text {str }}$ which quantifies the mean intensity of interspecific-competition within community, in the appropriate term of its multiplicative outcome upon the degree of species-abundance unevenness (see Box 1 in Appendix 3 for a schematic outline).

\subsection{About the Relative (Meta-) Stability of the Different Kinds of Niches' Displays}

The focal role of the "contiguous non-overlapping niche" pattern - broadly emanating from all the considerations above - is implicitly conducive to consider this pattern as playing the role of a kind of "attractor", as already rightly suggested in [58]. And this, despite natural communities can, however, remain apart from the ideal "contiguous non-overlapping niche" pattern (more or less transitorily and even durably) as a consequence of more or less intense interspecific-competition [64]. But being understood, yet, that natural selection is generally expected to finally favor the reduction of such interspecific-competition at niche-overlaps $[55,65]$.

As argued in [58], reducing niche-overlaps would likely contribute to the stability of natural communities: in substance, "better resource partitioning among co-occurring species, thanks to improved niche diversification, favors low niche (functional) overlaps and the relaxation of interspecific competition, therefore likely resulting in more stable species assemblages".

By contrast, severe interspecific-competition (strong contest for shared resource at large functional niche overlaps) is more likely conducive to instability of species-richness: indeed, severe interspecific-competition sharply enhances the degree of species-abundance unevenness and, thereby, especially depresses the level of lowest species-abundances. Which, in turn, may ultimately lead to the extinction of the rarer species [66] and thus, destabilizes species-richness. Additional empirical evidence supporting this envision also comes from reports by several authors $[40,59,64,67,68]$.

In particular, a detailed analysis of the recovery process of a reef-associated Gastropod community, previously submitted to thorough destruction by experimental nuclear blasts [59], provides demonstrative arguments in this 
respect, as shown in Figs 6 \& 7 . Clearly highlighted in these Figures is the onset of a transient but strong interspecific-competition, subsequently followed by a more or less progressive return to low levels of interspecificcompetition. A trend that has been advocated as being of rather general relevance by some authors $[2,66,69,70]$.

This is a strong empirical evidence of the attractive trend towards stabilization thanks to the reduction and ultimate cancel of interspecificcompetition $[68,71]$.

Yet, as already underlined, it is generally recognized that natural communities may often subsist in more or less non-equilibrium states, involving the remanence of appreciable interspecific-competition [60]. This is also apparent from the survey of 38 marine communities as shown above in Fig. 2 and further in Figs. $9 \& 10$. Indeed, many causes can contribute to prevent or at least to bridle the tendency towards low-competitive equilibrium, such as demographic cyclicity, predation hazards, fluctuations and instability in physical and biotic environment $[60,72]$ or, stochasticity in the continuous species recruitment [73].

\subsection{On the Relevance of the MACARTHUR Conception of Niche Display and Inter Specific-Competition}

According to MACARTHUR [53], when niche display corresponds to the "contiguous, nonoverlapping niche" pattern, the resulting absence of geometrical niche-overlaps prevents interspecific-competition (with, accordingly, a relatively even species abundance distribution, complying with the "broken-stick" model). Now, the increase in the number $S_{t}$ of co-occurring species - that is the increase of the (same) number of species-associated niches - will likely render the ideal niche-diversification increasingly difficult, likely triggering a progressive niche "overcrowding" and the resulting onset of nicheoverlaps. All other things remaining equal, the interspecific-competition within community is therefore expected to increase with higher species-richness $S_{t}$. And expected to increase also, with the overall density $D$ of individuals, since the intensity of contest among co-occurring species for shared resource at niche-overlaps is exacerbated by the density of individuals.

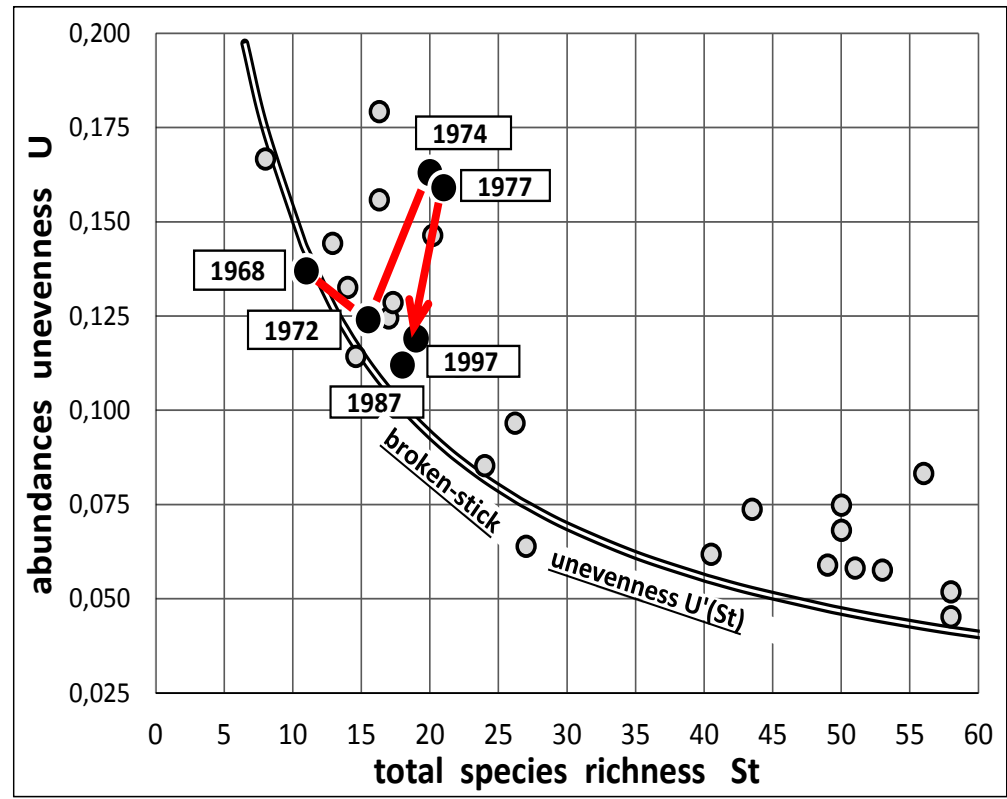

Fig. 6. Variations of the crude species-abundance unevenness $U$ and the true species-richness $S_{t}$ along the following recovery process, from 1968 (before destruction by nuclear testing) up to 1997: black discs. Also plotted, as a background context, is a series of other marine communities comprising either invertebrates or fishes: light-grey discs. Note, in particular, the transient substantial increase in species-richness, inducing in turn a strong increase in interspecific-competition, quantified by the transient sharp discard of unevenness $U$ from the corresponding unevenness $U$ ' $\left(S_{t}\right)$ of the "broken-stick" distribution and the final return to weak interspecific-competition (adapted from [59]. 


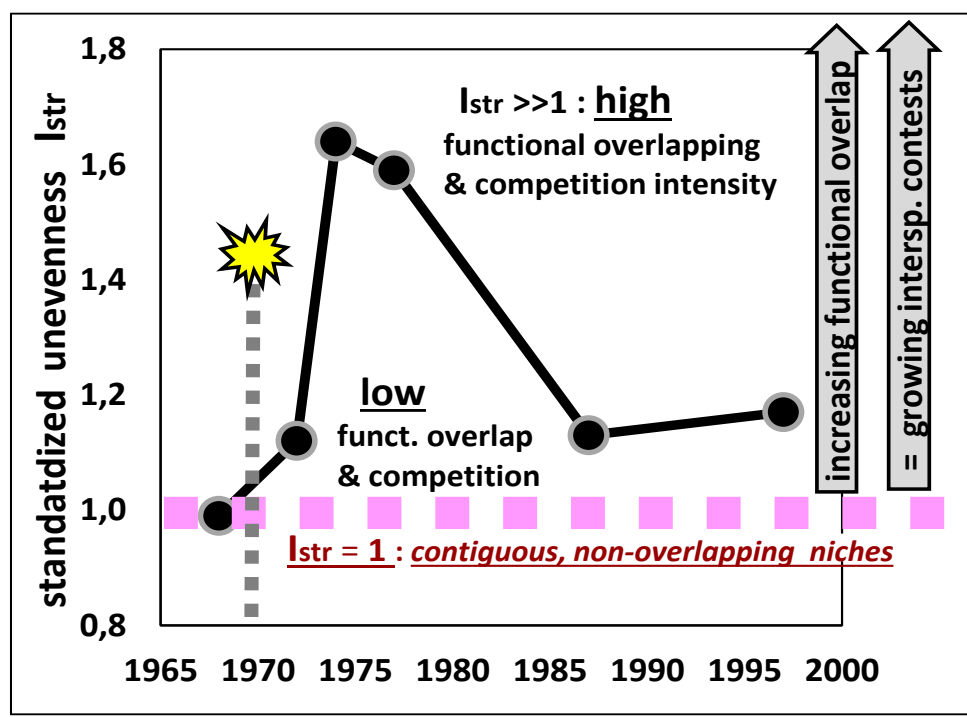

Fig. 7. Ecological interpretation of the variations in the intensity of interspecific-competition (quantified by the standardized abundance unevenness $I_{\text {str }}$ ) driven by the severity of interspecific-contests for shared resource at functional overlaps among partially intersecting niches. The degree of "functional overlap" depending on both (i) the extent of geometrical overlapping (promoted by increasing species-richness and the corresponding number of species-associated niches) and (ii) the density of individuals sharing the same kind of resource at niche overlaps (results according to [59])

This expected, positive correlation of $I_{\text {str }}$ with both $S_{t}$ and $D$, when all other things remain equal, deserves and can be tested empirically, provided appropriate field data is made available, that is the concomitant variations of both speciesrichness $S_{t}$ and the overall individuals-density $D$ on a same site. Such a rare opportunity is obtained by the monitored recovery of the reefassociated Gastropod community, reported in reference [59] and already considered in the preceding section. Based on the observed values of $I_{s t r}, S_{t}$ and $D$ along the recovery process, a linear regression of $I_{s t r}$ against $S_{t}$ and $D$ yields:

$I_{s t r}=0.0794 S_{t}+0.1987 D-0.740$

the regression being statistically significant as regards the dependence of $I_{\text {str }}$ upon both (i) the species-richness St: $t$-test, $\mathrm{df}=2, \mathrm{t}=10.0, \mathrm{p}=$ 0.01 and (ii) the overall density $D$ of individuals per unit of area $\left(\mathrm{m}^{2}\right)$ : $t$-test, $\mathrm{df}=2, \mathrm{t}=4.6, \mathrm{p}=$ 0.04 .

This linear regression not only fairly well complies with qualitative expectations regarding the respective, positive roles of species richness $S_{t}$ and individuals' density $D$ in promoting interspecific-competition within the community. It further exhibits a fairly good quantitative fit with the observed data: Fig. 8. This provides additional empirical support - now in precise quantitative terms - to the rationally expected positive answer of standardized unevenness $I_{\text {str }}$ (reliably accounting for the intensity of interspecific-competition) to both speciesrichness $S_{t}$ and overall density of individuals $D$.

Finally, this result provides complementary convincing support in favor of the niche-pattern appraisal of species organization within communities (as opposed, incidentally, to the purely stochastic view advocated by the socalled "Neutral Theory", at least when the latter theory is considered stricto-sensu).

And - still more precisely - the results above clearly comply fairly well with the conception developed by MACARTHUR, in his seminal paper on the subject [53]. In particular, the results highlighted in both sections $\S 3.5 \& 3.6$ jointly provide strong empirical support to the interpretation of the broken-stick model of abundances distribution as relevantly reflecting the "contiguous, non-overlapping" niche pattern advocated by MACARTHUR, thereby clearly dismissing other alternative interpretations of the broken-stick distribution, formerly put forward [74] (and already duly criticized in [75]). 


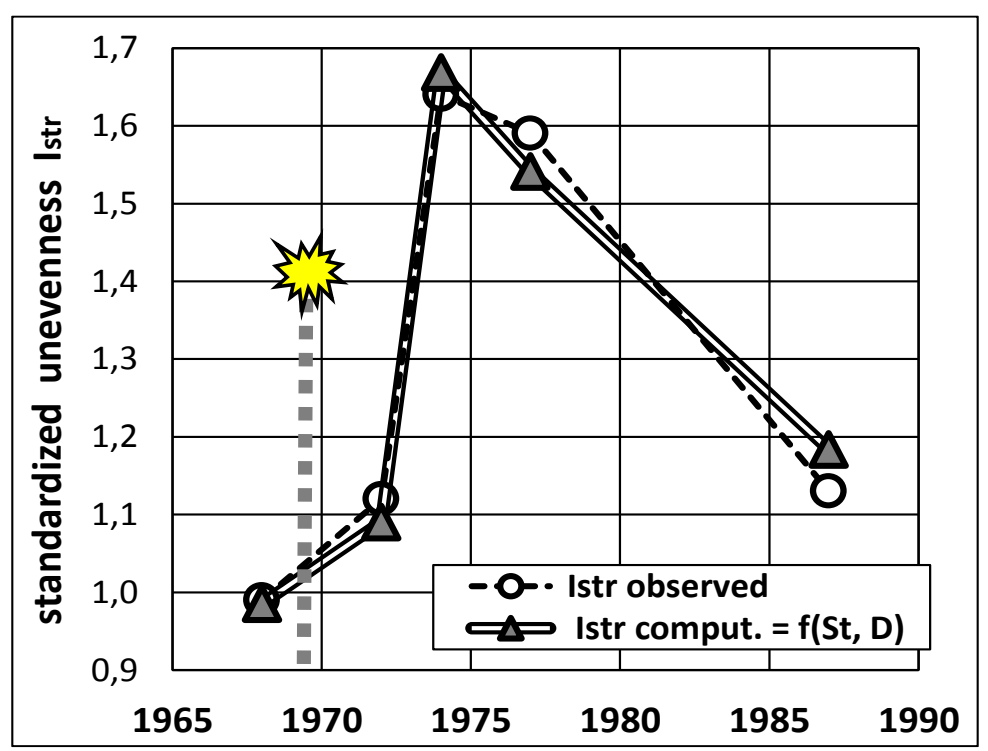

Fig. 8. Comparison between the observed and the computed variations of the intensity of interspecific competition (aptly quantified by the standardized abundance unevenness $I_{\text {str }}$ ) with $S_{t}$ and D. As observed: white discs; as computed according to equation (4): grey triangles.

\subsection{Deriving Suggestive Relationships between the Main Parameters Driving the Hierarchic Organization among Species within Community}

Based on the solid foundations just highlighted above, one can envisage establishing some suggestive quantitative relationships between:

- on the one hand, the species-richness $S_{t}$ and the overall density $\mathrm{D}$ of individuals, as the input data, and

- on the other hand, a series of parameters characterizing the species organization within community, such as: (i) the crude speciesabundance unevenness $\mathrm{U}$, (ii) the degree of "species-packing" (1/U) [76-79], that is the degree of niche-diversification and the resulting refined resource-partitioning [56,76,80-86], (iii) the intensity of interspecific-competition, aptly quantified by the standardized abundanceunevenness $\mathrm{I}_{\text {str, }}$ (iv) the lowest relative abundance ast, $(\mathrm{v})$ the lowest density (= absolute abundance ) dst. The latter being of particular practical concern, as it is expected to condition, in turn, the subsistence of the rarer species (in particular with reference to the "Allee effects" thresholds $[87,88])$ - thereby determining the expected degree of resilience of the level of species-richness.

In this perspective, empirical data derived from the recovery process of the reef-associated gastropod community [59] leads to the following empirical relationships:

${ }^{*} \mathbf{I}_{\text {str }}=0.0794 . S_{t}+0.1987 . D-0.740$

${ }^{*} a_{\mathrm{st}}=0.00195 . D .\left(I_{\mathrm{str}}\right)^{-6.63}$, that is:

$$
\begin{aligned}
& { }^{*} \mathrm{a}_{\mathrm{St}}=0.00195 . \mathrm{D} /\left(0.0794 . \mathrm{S}_{\mathrm{t}}+0.1987 . \mathrm{D}-\right. \\
& 0.740)^{6.63}
\end{aligned}
$$

The two relations above being, each, empirically derived from the regression (i) of $I_{\text {str }}$ with respect to $S_{t}$ and $D$ and (ii) the regression of ast with respect to $D$ and $I_{\text {str }}$, using empirical data from [59].

Then, the two relations below are directly derived from the two preceding ones:

$$
\begin{aligned}
& { }^{*} d_{S t}=a s t . D=0.00195 . D^{2} .\left(I_{s t r}\right)^{-6.63}, \text { that is: } \\
& * d_{s t}=0.00195 . D^{2} /\left(0.0794 . S_{t}+0.1987 . D-\right. \\
& 0.740)^{6.63}
\end{aligned}
$$

${ }^{*}[\mathbf{1} / \mathrm{U}]=\left(1 / \mathrm{U}^{\prime}\left(\mathrm{S}_{\mathrm{t}}\right)\right) \cdot\left(1 / \mathrm{Istr}_{\mathrm{str}}\right)$, that is (accounting for result in Appendix 2):

${ }^{*}[\mathbf{1} / \mathbf{U}]=\left(1.006 . \mathrm{S}^{+0.767}\right) /\left(0.0794 . S_{t}+0.1987 . \mathrm{D}-\right.$ $0.740)$

And, more generally:

$$
\begin{aligned}
& { }^{*} I_{s t r}=a \cdot S_{t}+b \cdot D-c \\
& { }^{*} a_{s t}=e \cdot D /\left(a \cdot S_{t}+b \cdot D-c\right)^{\dagger}
\end{aligned}
$$


${ }^{*} \mathbf{d}_{\mathrm{st}}=\mathrm{e} \cdot \mathrm{D}^{2} /\left(\mathrm{a} \cdot \mathrm{S}_{\mathrm{t}}+\mathrm{b} \cdot \mathrm{D}-\mathrm{c}\right)^{\mathrm{f}}$

${ }^{*}[\mathbf{1} / \mathbf{U}]=\left(\mathrm{g} \cdot \mathrm{S}_{\mathrm{t}}^{\mathrm{h}}\right) /\left(\mathrm{a} \cdot \mathrm{S}_{\mathrm{t}}+\mathrm{b} \cdot \mathrm{D}-\mathrm{c}\right)=\left(1.006 . \mathrm{S}_{\mathrm{t}} 0.767\right)$ $/\left(a . S_{t}+b . D-c\right)$

with, among the coefficients 'a', 'b', 'c', 'e', 'f', ' $g$ ':

- ' $a$ ' and 'b', being essentially positive, in accordance with the frame of the nichepattern hypothesis;

- 'e' and 'f', being obviously positive to make sense;

- ' $g$ ' and ' $h$ ' remaining unchanged $(g=1.006, h$ $=0.767$ ), since these coefficients are two characteristics of the broken-stick model;

- the sign of ' $c$ ' cannot be prescribed but, yet, remains such that $\left(a . S_{t}+b . D-c\right)$ remains always essentially positive.

\section{DISCUSSION}

Following both the theoretical argumentation and the empirical evidence provided above, the newly conceived "standardized" unevenness index, Istr, benefits from being relevant and self-significant at both the descriptive and the interpretative points of view. Thereby complying with those requirements already claimed by many authors [5-18]. Requirements, however, having remained unsatisfied, up to now, by conventional metrics of abundance (un-) evenness.

Namely:

(i) the standardized unevenness index, $I_{\text {str, }}$ is cleared out from the overall trend for (negative) dependence of the crude abundance unevenness $U$ upon species-richness: accordingly, the standardized unevenness $I_{\text {str }}$ on the one hand, and the total species-richness $S_{t}$ on the other hand, are truly complementary, instead of being, partly redundant descriptors, as is the case with crude abundance-unevenness $U$ - and more generally with all conventional (un-) evenness metrics.

With the resulting major practical advantage that the standardized unevenness index now makes intrinsic sense, as required in particular in [10], thus allowing reliable (non-biased) comparisons between communities, whatever their differences in species-richness. This remarkable and desirable property of the standardized index $I_{\text {str }}$ having been achieved by opportunely standardizing the crude unevenness $U$ to the broken-stick unevenness U', after having recognized the latter as precisely conveying the part of the crude unevenness which is formally dependent on species-richness, as empirically highlighted in Fig. 2. This being also further supported, on a theoretical basis, by the demonstration of the entire and univocal dependence of the broken-stick unevenness U' upon species-richness [9,53,54], see also Appendix 2.

(ii) the standardized unevenness index, $\mathrm{I}_{\text {str }}$, is self-significant at the ecological point of view, since this index relevantly reflects the proper contribution of interspecific-competition intensity to the degree of abundance-unevenness. The intensity of interspecific-competition being all the stronger than $I_{\text {str }}$ exceeds unity - with competition being understood as the result of interspecific contests for shared resource arising among species co-occurring at functional niche overlaps (following the classical theoretical framework proposed by MACARTHUR in his seminal paper [53]).

Note that the theoretical framework by MACARTHUR - despite having been challenged in the past on the basis of speculative argumentations [74] (but see [75]) - receives, here, still further empirical support from the evidence provided in Figs 6 \& 7, successfully replicated in Fig. 8. Empirical evidence fairly well complies with the schematic interpretative background highlighted in Figs 3 \& 4 .

Moreover, and most interestingly, this highlights that the baseline position of the "broken-stick" unevenness, with respect to the overall distribution of crude unevenness $U$ in a large series of marine communities (see Fig. 2), is far from being coincidental but, indeed, deeply rooted in the ecological process which rules the hierarchized internal structuration of species within natural communities (see also Appendix 3).

In other words, beyond the varying intensity of interspecific-competition among natural communities (usually within the range $0.8<\mathrm{I}_{\text {str }}<$ 2, see Figs 9 \&10), it is definitely the ideal pattern of "contiguous non-overlapping niche" - i.e. the absence of interspecific-competition - which actually provides impetus to (and thus explains) the trend for decrease of the crude abundance unevenness $U$ with increasing species richness $\mathrm{S}_{\mathrm{t}}$. A trend which becomes obvious as soon as a sufficiently large range of variation of species richness is considered, as clearly highlighted in Figs 1 and 2. 


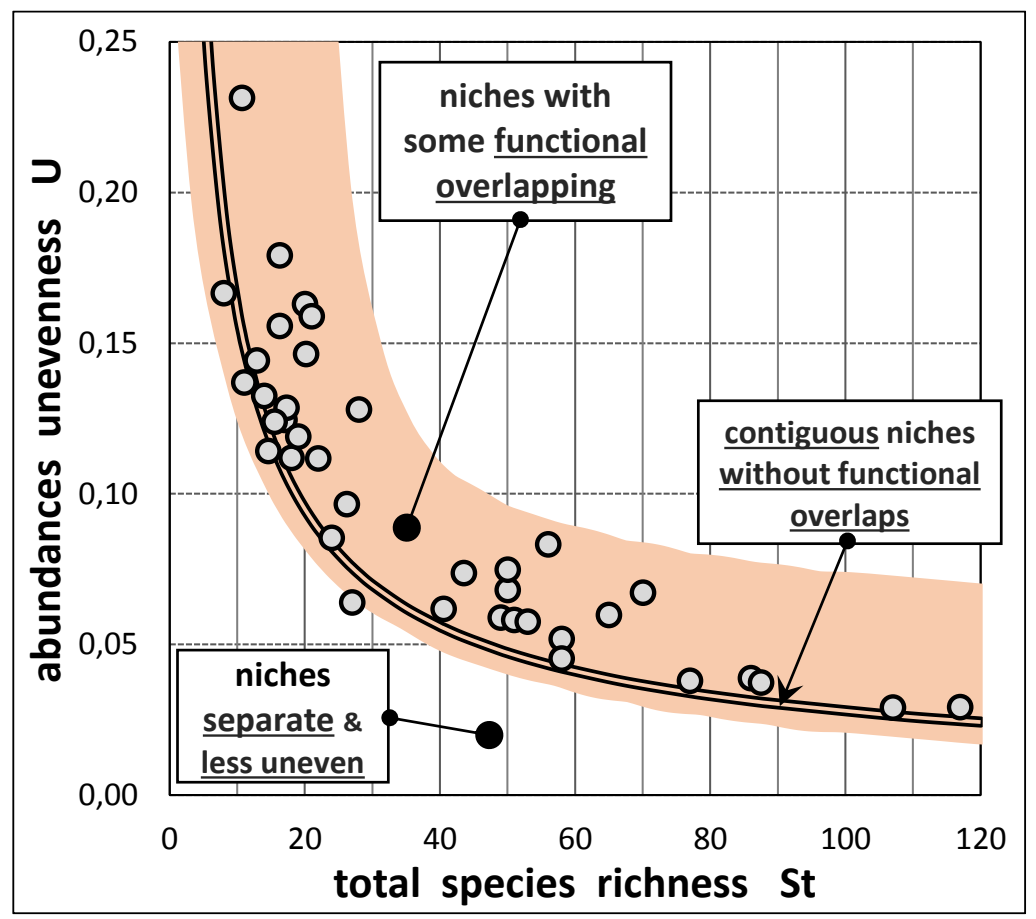

Fig. 9. Crude species abundance unevenness $U$ plotted against total species richness $S_{t}$ for 38 marine communities (as shown in Fig. 2), superimposed upon the interpretative frame proposed in Fig. 3.

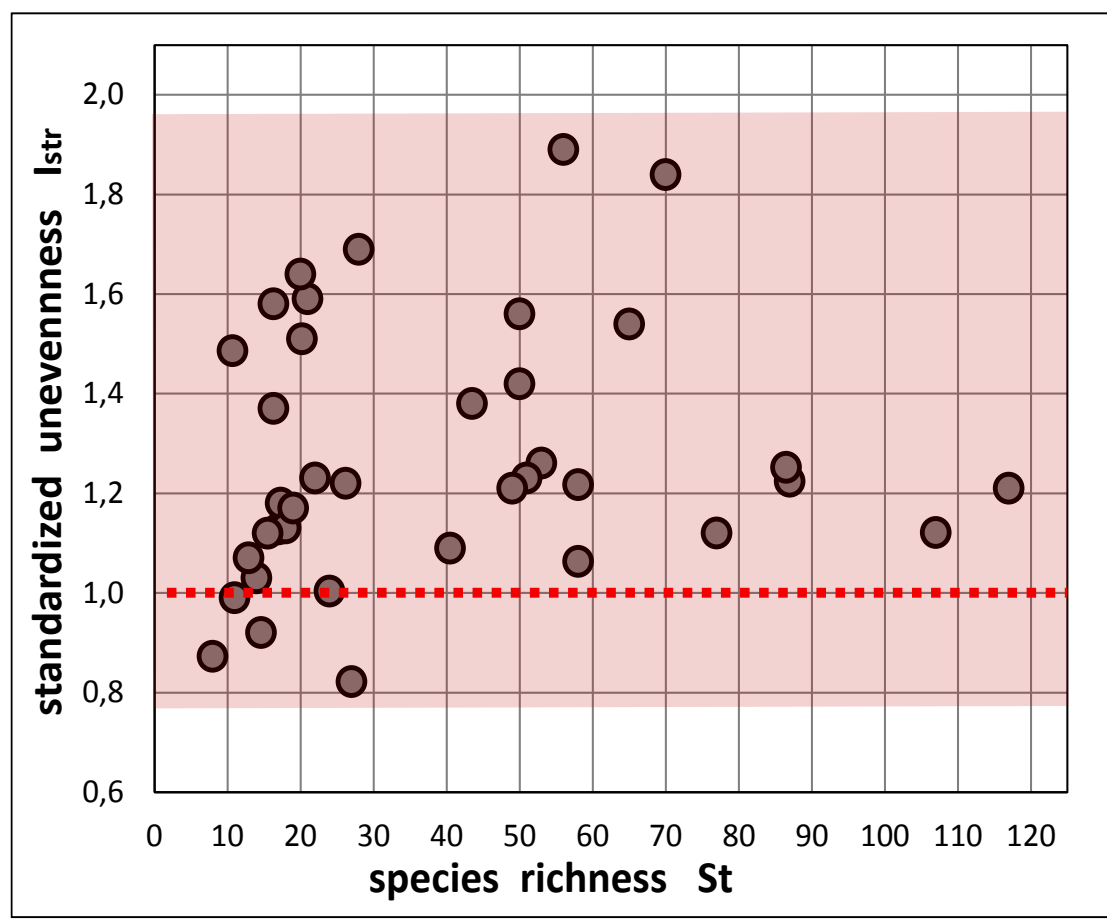

Fig. 10. The "standardized abundance unevenness" $I_{\text {str }}$ plotted against total species richness $S_{t}$ for 38 marine communities (after [42-52]).

A final remark: the central role plaid by the "broken-stick" model - deeply rooted in the process of internal organization of species within communities - may seem surprising, since it is now commonly admitted that species abundance distributions generally better fit the "log-normal" 
model that any other kinds of models [54,89-92]. Yet, in fact, there is no inconsistency at all, because the "broken-stick" distribution actually merges fairly well into the "log-normal" family, within which the "broken-stick" represents, simply, a special case - as further argued in Appendix 4.

\section{CONCLUSION}

Splitting the "crude" (as-recorded) abundance unevenness $U$ into two contributions, the "broken-stick" unevenness U'( $\left.\mathrm{S}_{\mathrm{t}}\right)$ mathematically related to species-richness $S_{t}-$ and the "standardized" unevenness $I_{\text {str }}$ - formally independent of species-richness - has first answered practical purposes. Thus, thanks to having disentangle the standardized unevenness, $I_{\text {str }}$, from the crude unevenness $U$, it becomes now possible:

(i) to make relevant comparisons of speciesabundance unevenness between communities whatever their differences in species richness, thereby conferring to the standardized unevenness index $I_{\text {str }}$ a true descriptive representativeness - while this is not allowed with the crude unevenness $U$ and, more generally, with any of the conventional metrics of abundance (un-) evenness;

(ii) to uncover the specific contribution to the level of species abundance unevenness of the intensity of interspecific-competition, triggered by contests among species exploiting a same shared resource at niche-overlaps any).

This, indeed, is of major interest, since none of the conventional descriptors of speciesabundance unevenness - by lacking standardization - can relevantly satisfy the two fundamental objectives of reaching true descriptive representativeness and allowing ecological self-significance (in term of the consequence of the severity of interspecificcompetition on the degree of species-abundance unevenness).

Beyond the practical purposes just evoked above - addressing a more general appraisal of the processes involved in the internal organization within species communities - the splitting of abundance unevenness in its two (multiplicative) components - U'( $\left.S_{t}\right)$ and $I_{s t r}-$ clearly disentangles and highlights separately: (i) what does contribute to reduce the unevenness of species abundances, namely an improved niche diversification relevantly quantified by $\left[1 / U^{\prime}\left(S_{t}\right)\right]$ which measures the degree of species "packing" [77,93],

(ii) from what contributes, on the contrary, to (multiplicatively) increase the unevenness of species abundances, namely the intensity of interspecific competition.

With this essential remark that:

- while the contribution "Istr" of interspecific competition is of purely deterministic nature and, as such, is idiosyncratically attached to the particular community under consideration,

- the contribution [1/U'( $\left.\left.\mathrm{S}_{\mathrm{t}}\right)\right]$ of improved niches diversification - although being also deterministic in essence - can yet be fairly well accounted for in simply stochastic terms (i.e. the "broken-stick" process of niches' apportionment to co-occurring species), as a univocal function of the species-richness, whatever the other characteristics of the community, as thoughtfully suggested by MACARTHUR [53].

Moreover, strongly supported by empirical evidence - the central role played by the "broken-stick" model in this interpretative approach thus fairly complies with MACARTHUR conception of species-abundance distribution in relation with geometrical niches' display.

Thereby providing renewed credit to MACARTHUR original intuitions.

\section{ACKNOWLEDGEMENTS}

I acknowledge the fruitful comments of three anonymous Reviewers.

\section{COMPETING INTERESTS}

Author has declared that no competing interests exist.

\section{REFERENCES}

1. Laird RA. The use of relative abundance patterns to discriminate among niche apportionment processes. Community Ecology. 2002; 3(1): 31-38.

2. Graham JH, Duda JJ. The humpbacked species richness curve: A contingent rule for community ecology. International Journal of Ecology. 2011; id868426.

3. Kery M, Royle JA. Inference about species richness and community structure 
using species-specific occupancy models in the National Swiss Breeding Bird survey MUB. Proceedings of the EURING Technical Meeting and Workshop, Dunedin, New Zealand; 2007.

4. Shimadzu H, Darnell R. Attenuation of species abundance distributions by sampling. Royal Society Open Science. 2015; 2: 140219 .

5. Johnson MP, Raven PH. Natural regulation of plant species diversity. Evolutionary Biology. 1970; 4:127-162.

6. Berger WH, Parker FL. Diversity of planktonic Foraminifera in deep-sea sediments. Science. 1970; 168: 13451347.

7. De Benedictis PA. On the correlations between certain diversity indices. The American Naturalist. 1973; 107:295-302.

8. Heip C. A new index measuring evenness. Journal of the Marine Biology Association U.K. 1974; 54: 555-557.

9. May RM. Patterns of species abundance and diversity. In Cody ML, Diamond JM. Ecology and evolution of communities. The Belknap Press of Harvard University. 1975; 81-120.

10. Smith B, Wilson JB. A consumer's guide to evenness indices. Oikos. 1996;76: 7082.

11. Stirling G, Wilsey B. Empirical relationships between species richness, evenness and proportional diversity. The American Naturalist. 2001; 158(3):286299.

12. Buzas MA, Hayek LAC. On richness and evenness within and between communities. Paleobiology. 2005; 31(2): 199-220.

13. Loiseau N, Gaertner JC. Indices for assessing coral reef fish biodiversity: The need for a change in habits. Ecology and Evolution. 2015; 5(18): 4018-4027.

14. Röpke CP, Amadio S, Zuanon J, Ferreira EJG, Pereira de Deus C, Pires THS, Winemiller KO. Simultaneous abrupt shifts in hydrology and fish assemblage structure in a floodplain lake in the central Amazon. Scientific Reports. 2017; 7: 40170.

15. Komonen A, Elo M. Ecological response hides behind the species abundance distribution: Community response to lowintensity disturbance in managed grasslands. Ecology and Evolution. 2017; 7:8558-8566.

16. Béguinot $J$. The hierarchical structuring of species abundances within communities: disentangling the intensity of the underlying structuring process behind the apparent unevenness pattern. Advances in Research. 2018; 16(1): 1-12.

DOI: $10.9734 / A I R / 2018 / 43918$

17. Su Q. A relationship between species richness and evenness that depends on specific relative abundance distribution. Peer J. 2018; 6: e4951.

18. Robinson JPW, White ER, Wiwchar LD, Claar DC, Suraci JP, Baum JK. The limitations of diversity metrics in directing global marine conservation. Marine Policy. 2014; 48: 123-125.

19. Brose U, Martinez ND, Williams RJ. Estimating species richness: sensitivity to sample coverage and insensitivity to spatial patterns. Ecology. 2003; 84(9): 2364-2377.

20. Béguinot J. An algebraic derivation of Chao's estimator of the number of species in a community highlights the condition allowing Chao to deliver centered estimates. ISRN Ecology. 2014; article ID 847328, DOI: 10.1155/2014/847328; <hal01101415>

21. Béguinot $J$. When reasonably stop sampling? How to estimate the gain in newly recorded species according to the degree of supplementary sampling effort. Annual Research \& Review in Biology. 2015;7(5): 300-308;

DOI: 10.9734/ARRB/2015/18809; <hal01228695>

22. Béguinot $\mathrm{J}$. Theoretical derivation of a bias-reduced expression for the extrapolation of the Species accumulation curve and the associated estimation of total species richness. Advances in Research. 2016; 7(3): 1-16.

DOI: $10.9734 / \mathrm{AIR} / 2016 / 26387$; <hal01367803>

23. Béguinot J. Extrapolation of the species accumulation curve associated to "Chao" estimator of the number of unrecorded species: a mathematically consistent derivation. Annual Research \& Review in Biology. 2016; 11(4): 1-19.

doi: 10.9734/ARRB/2016/30522; $<$ hal 01477263 >

24. Béguinot J. On general mathematical constraints applying to the kinetics of species discovery during progressive sampling: Consequences on the theoretical expression of the Species Accumulation Curve. Advances in Research. 2016; 8(5): 1-17. 
DOI: $10.9734 / \mathrm{AIR} / 2016 / 31791$.

$<$ hal 01516141>

25. $\mathrm{Li} \mathrm{CT}$, Li K-H. Species Abundance Distribution and Species Accumulation Curve: A general framework and results. arXiv. 2020; 2011.07270v1 [stat. AP].

26. Béguinot J. How to extrapolate Species Abundance Distributions with minimum bias when dealing with incomplete species inventories. Advances in Research. 2018; 13(4): 1-24.

DOI: $10.9734 / A I R / 2018 / 39002$

27. Rumohr H, Karakassis I, Jensen JN. Estimating species richness, abundance and diversity with 70 macro-benthic replicates in the Western Baltic Sea. Marine Ecology Progress Series. 2001; 214: 103-110.

28. Fontaine $B$, Bouchet $\mathrm{P}$. et al. The European Union's 2010 target: putting rare species in focus. Biodiversity and Conservation. 2007;139:167-185.

29. Flöder S, Jaschinski S, Wells G, Burns CW. Dominance and compensatory growth in phytoplankton communities under salinity stress. Journal of Experimental Marine Biology and Ecology. 2010; 395: 223-231.

30. Bracken M, Low N. Realistic losses of rare species disproportionately impact higher trophic levels. Ecology Letters. 2012; 15: 461-467.

31. Mouillot D, Bellwood DR, Baraloto C, Chave J, Galzin R, Harmelin-Vivien M, Kulbicki M, Lavergne S, Lavorel S, Mouquet N, Paine CET, Renaud J, Thuiller W. Rare species support vulnerable functions in high-diversity ecosystems. PLoS Biol. 2013; 11(5): e1001569.

32. Jain M, Flynn DFB, Prager CM, Hart GM, De Van CM, Ahrestani FS, Palmer MI, Bunker DE, Knops JHM, Jouseau CF, Naeem S. The importance of rare species: a trait-based assessment of rare species contribution to functional diversity and possible ecosystem function in tall-grass prairies. Ecology and Evolution. 2014; 4(1):104-112.

33. Ignatiades L, Gotsis-Skretas $\mathrm{O}$. The contribution of rare species to coastal phytoplankton assemblages. Marine Ecology. 2014; 35: 132-145.

34. Low-Decarie $E$, Kolber M, Homme $P$, Lofano A, Dumbrell A, Gonzalez A \& Bell G. Community rescue in experimental communities. Proceedings of the National
Academy of Sciences USA. 2015; 112(46): 14307-14312.

35. Leitao RP, Zuanon J, Villéger S, Williams SE, Baraloto C, Fortunel C, Mendonça FP, Mouillot D. Rare species contribute disproportionately to the functional structure of species assemblages. Proceedings of The Royal Society B. 2016; 283: e0084.

DOI: $10.1098 / \mathrm{rspb} .2016 .0084$

36. Violle C, Thuillier W, Mouquet N, Munoz F, Kraft NJB, Cadotte MW, Livingstone SW, Mouillot D. Functional rarity: The ecology of outliers. Trends in Ecology; 2017.

DOI: 10.1016/j.tree.2017.02.002

37. Cao Y, Williams DD, Williams NE. How important are rare species in aquatic community ecology and bioassessment? Limnology and Oceanography. 1998; 43(7): 1403-1409.

38. Willis A. Rarefaction, alpha diversity and statistics. Bio Rxiv; 2017.

DOI: $10.1101 / 231878$

39. Strong WL. Assessing species abundance unevenness within and between plant communities. Community Ecology. 2002; 3(2): 237-246.

DOI: 10.1556/COMEC.3.2002.2.9

40. Magurran AE. The commonness and rarity of species. in Measuring Biological Diversity. Blackwell Publishing Ltd; 2004.

41. Grzès IM. Ant species richness and evenness increase along a metal pollution gradient in the Boleslaw zinc smelter area. Pedobiologia. 2009; 53: 65-73.

42. Béguinot J. Numerical extrapolation of the species abundance distribution unveils the true species richness and the hierarchical structuring of a partially sampled marine gastropod community in the Andaman Islands (India). Asian Journal of Environment and Ecology. 2018; 6(4):123. DOI: $10.9734 / A J E E / 2018 / 41293$ <hal01807454>

43. Béguinot J. The full hierarchical structuration of species abundances reliably inferred from the numerical extrapolation of still partial samplings: a case study with marine snail communities in Mannar Gulf (India). Asian Journal of Environment and Ecology. 2018; 7(3): 127. DOI: $109734 /$ AJEE/2018/36831

44. Béguinot J. Analyzing the role of environmental stresses on species richness and the process of hierarchical structuring of species abundances in marine Gastropods communities at Suva 
(Fiji Islands). International Journal of Environment and Climate Change. 2018; 8(3): 200-233.

45. Béguinot J. Inferring total species richness and the exhaustive hierarchical structuring of species abundances in tropical Sea-Stars communities (Asteroidea), using numerical extrapolation of partial inventories. Asian Journal of Environment and Ecology. 2018; 8(2): 125. DOI: $109734 / A J E E / 2018 / 46272$

46. Béguinot J. Comparing the complete hierarchical structuration of species abundances in reef fish communities according to coral morphology, using the numerical extrapolation of only incomplete inventories. Asian Journal of Environment and Ecology. 2018; 8(1): 1-20.

DOI: 109734/AJEE/2018/45402

47. Béguinot J. Influence of coral architecture on species richness and the hierarchical structuration of species abundances in reef fish communities: A case study in the Eastern Tropical Pacific. Asian Journal of Environment \& Ecology. 2018; 8(3):121.

doi.org/10.9734/ajee/2018/v8i330075

48. Béguinot J. Influence of fishing activity on the total species richness and the abundance unevenness in reef fish communities: a case study in a Brazilian tropical coral complex. International Journal of Environment and Climate Change. 2019; 9(1): 58-76.

49. Béguinot J. Influence of coral complexity on species richness and the hierarchical structuration of species abundances in reef fish communities: A case study in southeast Brazil. Asian Journal of Environment \& Ecology. 2019; 9(3): 1-20.

DOI: 10.9734/AJEE/2019/v9i330098

50. Béguinot J. Influence of environmental heterogeneity on the species composition, species richness and species abundances unevenness in reef-associated conus communities (Neogastropoda) from Papua New Guinea. Asian Journal of Environment \& Ecology. 2019; 10(3): 1-21.

DOI: 10.9734/AJEE/2019/v10i330116

51. Béguinot J. Variations in total species richness and the unevenness of species abundance distribution between two distant Conus communities (Neogastropoda): A case study in Mannar Gulf (India). Asian Journal of Environment \& Ecology. 2019; 9(4): 1-18.

DOI: 10.9734/AJEE/2019/v9i430102
52. Béguinot J. Inferring true species richness and complete abundance distribution in six reef-fish communities from Red-Sea, using the numerical extrapolation of incomplete samplings. Asian Journal of Environment \& Ecology. 2019; 11(3): 1-21.

DOI: 10.9734/AJEE/2019/v11i330136

53. MacArthur $\mathrm{RH}$. On the relative abundance of bird species. Proceedings of the National Academy of Sciences U.S.A. 1957; 43: 293-295.

54. Béguinot J. Disentangling and quantifying the functional determinants of species abundance unevenness in ecological communities. Advances in Research. 2019; 19(1): 1-14.

DOI: $10.9734 / A I R / 2019 / v 19 i 130114$

55. Holt RD. On the relation between niche overlap and competition: the effect of incommensurable niche dimensions. Oikos. 1987; 48:110.

56. Granot I, Belmaker J. Niche breadth and species richness: correlation strength, scale and mechanisms. Global Ecology and Biogeography. 2019;00:1-12,

DOI: 10.1111/geb.13011

57. Garcia K, Sanpera C, Jover L, Palazon S, Gosalbez J, Gorski K, Melero Y. High trophic niche overlap between a native and invasive mink does not drive trophic displacement of the native mink during invasion process. Animals. 2020; 10: 1387. DOI: 10.3390/ani10081387

58. Badali M, Zilman A. Effects of niche overlap on coexistence, fixation and invasion in a population of two interacting species. Royal Society open science 2020 ; 7: 192181.

59. Béguinot J. Progressive recovery of a marine Gastropod community following atmospheric nuclear tests in FrenchPolynesia: A socio-ecological interpretation. Annual Research \& Review in Biology. 2021; 36(1): 77-110; DOI: 10.9734/ARRB/2021/v36i130335

60. Huston M. A general hypothesis of species diversity. The American Naturalist. 1979; 113(1): 81-101.

61. FesI C. Niche-oriented species-abundance models: different approaches of their application to larval chironomid (Diptera) assemblages in a large river. Journal of Animal Ecology. 2002; 71: 1085-1094.

62. Sugihara G, Bersier L-F, Southwood TR, Pimm SL, May RM. Predicted correspondence between species 
abundances and dendrograms of niche similarities. Proceedings of the National Academy of Sciences U.S.A. 2003; 100(9) :5246-5251.

63. Begon $M$, Howarth $R$, Townsend $C R$. Essentials of Ecology [Patterns in Species Richness]. Wiley Publishing House; 2014.

64. King CE. Relative abundance of species and MacArthur's model. Ecology. 1964; 45: 716-727.

65. Chesson P. Mechanisms of maintenance of species diversity. Annual Review of Ecology, Evolution and Systematics. 2000; 31: 343-366.

66. Jackson ST, Sax DF. Balancing biodiversity in a changing environment: extinction debt, immigration credit and species turnover. TREE. 2009; 1196.

67. De Vita J. Niche separation and the broken-stick model. The American Naturalist. 1979; 114(2):171.

68. Wilson JB, Wells TCE, Trueman IC, Jones G, Atkinson MD, Crawley MJ, Dodd ME, Silvertown J. Are there assembly rules for plant species abundances? An investigation in relation to soil resources and successional trends. Journal of Ecology. 1996; 84: 527-538.

69. Revilla T, Weissing FJ. Non equilibrium coexistence in a competition model with nutrient storage. Ecology. 2008;89(3): 865877.

70. Martorell C, Freckleton RP. Testing the roles of competition, facilitation and stochasticity on community structure in a species-rich assemblage. Journal of Ecology. 2014; 102: 74-85.

71. Peters SE. Evenness of CambrianOrdovician benthic marine communities in North America. Paleobiology. 2004; 30(3): 325-346.

72. MacArthur $\mathrm{RH}$, Levins $\mathrm{R}$. The limiting similarity, convergence and divergence of coexisting species. The American Naturalist. 1967; 101(921).

73. Pedruski MT, Fussmann GF, Gonzales A. Predicting the outcome of competition when fitness inequality is variable. Royal Society Open Science. 2015; 2: 150274.

74. Cohen JE. Alternate derivations of a species-abundance relation. The American Naturalist. 1968; 102(924).

75. Ghent AW, Hanna BP. Application of the broken-stick" formula to the prediction of random time intervals. The American Midland Naturalist .1968; 79(2): 273-288.
76. Schoener TW. Resource partitioning in ecological communities. Science. 1974; 185: 27-39.

77. Heck KL. Some critical considerations of the theory of species packing. Evolution Theory. 1976; 1: 247-258.

78. Pigot AL, Trisos CH, Tobias JA. Functional traits reveal the expansion and packing of ecological niche space underlying an elevational diversity gradient in passerine birds. Proceedings of the Royal Society B. 2015; 283: 20152013.

79. Van de Perre F, Willig MR, Presley SJ, Mukinzi JC, et al. Functional volumes, niche packing and species richness: Biogeographic legacies in the Congo Basin. Royal Society Open Science. 2020; 7: 191582.

80. Pianka EC. Niche overlap and diffuse competition. Proceedings of the National Academy of Sciences USA. 1974; 71(5): 2141-2145.

81. Roughgarden J. Resource partitioning among competing species - A coevolutionary approach. Theoretical Population Biology. 1976; 9(3):388-424.

82. Pacala S, Roughgarden J. Resource partitioning and interspecific competition in two two-species insular Anolis Lizard communities. Science. 1982; 217:444-446.

83. Petchey L, Gaston KJ. Functional diversity (FD), species richness and community composition. Ecology Letters. 2002; 5: 402-411.

84. Halpern BS, Floeter SR. Functional diversity responses to changing species richness in reef fish communities. Marine Ecology Progress Series. 2008; 364: 147156.

85. Dexiecuo A, Chengjin C, Farnon EMD, Rui $\mathrm{H}$, Gang W. Migration and niche partitioning simultaneously increase species richness and rarity. Ecological Modelling. 2013; 258(C): 33-39.

86. Li Y, Shipley B, Price JN, De Dantas V, Tamme R, Westoby $M$, et al. Habitat filtering determines the functional niche occupancy of plant communities worldwide. Journal of Ecology 2018; 106(3): 1001-1009.

87. Zhou SR, Zhang DY. Allee effects and the neutral theory of biodiversity. Functional Ecology. 2006; 20: 509-513.

88. Gascoigne J, Berec L, Gregory S, Courchamp F. Dangerously few liaisons: A review of mate-finding Allee effects. Population Ecology. 2009; 51: 355-372. 
89. Loreau M. Species abundance patterns and the structure of ground-beetle communities. Ann. Zool. Fennici. 1992; 28: 49-56.

90. Magurran $A E$, Henderson PA. Explaining the excess of rare species in natural species abundance distributions. Nature. 2003; 422: 714-716.

91. Connolly SR, Hughes TP, Bellwood DR, Karlson RH - Community structure of corals and reef fishes at multiple scales. Science. 2005; 309: 1363-1365.

92. Ulrich $\mathrm{W}$, Soliveres $\mathrm{S}$, Thomas $\mathrm{AD}$, Dougill AJ, Maestre FT - Environmental correlates of species rank-abundance distributions in global drylands. Europe PMC Funders Group. 2016;20:56-64.

93. MacArthur R. Species packing and what interspecies competition minimizes.
Proceedings of the National Academy of Sciences U.S.A. 1969; 64(4):1369-1371.

94. McGill BJ, Etienne RS, Gray JS, et al. Species abundance distributions: moving beyond single prediction theories to integration within an ecological framework. Ecology Letters. 2007; 10: 995-1015.

95. Baldridge E, Harris DJ, Xiao X, White EP. An extensive comparison of species abundance distribution models. Peer J. 2016; 4e2823.

DOI: 10.7717/peerj.2823.

96. Chacon-Labella J, de la Cruz M, Escudero A. Evidence for a stochastic geometry of biodiversity: the effects of species abundance, richness and intraspecific clustering. Journal of Ecology. 2017;105:382-390 


\section{APPENDIX 1}

Demonstration that the variation of the overall range $R_{a}$ of species abundance is mainly related to the variations of the lowest species-abundance ast

The variations, with species-richness, of the overall range of species abundances, $R_{a}=\left[\log _{10}\left(a_{1}\right)-\right.$ $\log _{10}$ (ast)], are mainly driven by the corresponding variations of the lowest abundance ast. And, accordingly, the same holds true for the variations of the crude abundance-unevenness $U$. This is because the highest species-abundance, $a_{1}$, proves remaining quite less variable than is the lowest abundance, ast, as shown by Figure 11, from empirical data.

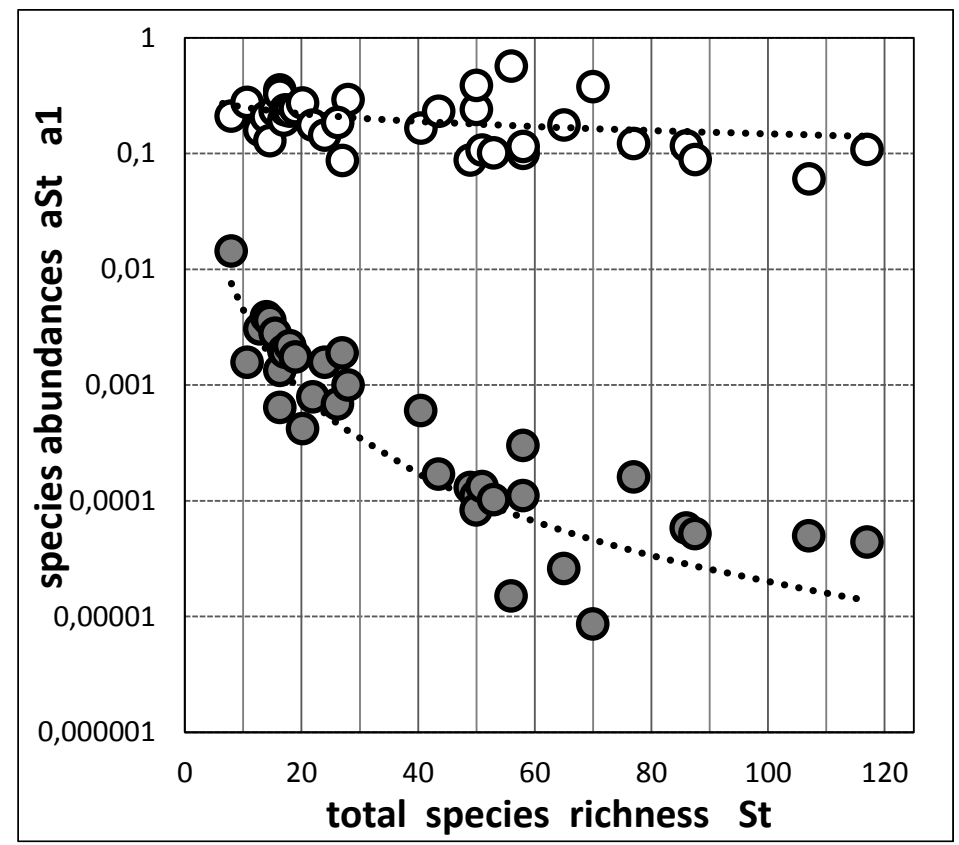

Fig. 11. The respective abundances of the dominant species $\left(a_{1}\right):$ white discs and of the rarest species ( $\left.a_{s_{t}}\right)$ : grey discs, both plotted against species richness $S_{t}$ for 38 marine communities (after [42-52]). As a trend, the increase with species-richness of the overall range of species abundance, $\mathbf{R}_{\mathrm{a}}=\left[\log _{10}\left(\mathrm{a}_{1}\right)-\log _{10}\left(\mathrm{a}_{\mathrm{st}}\right)\right]$, mainly results from the corresponding rapid decrease of the abundance $\left(a_{\mathrm{st}}\right)$ of the rarest species, while the abundance $\left(a_{1}\right)$ of the dominant species remains almost constant, comparatively.

This trend can, moreover, be generalized on theoretical basis. For the purpose of simplified demonstration, let consider an assemblage of species with a species-abundance distribution ideally fitting a geometric series, with a constant ratio ' $k$ ' $=a_{i} / a_{i+1}$ between the abundances of two successive species, $i$ and $i+1$, ranked by their decreasing values of abundance. It comes for the most and the least abundant species $\mathrm{a}_{1}$ and ast:

$$
\mathrm{a}_{1}=\left(\mathrm{k}^{\mathrm{St}}-\mathrm{k}^{\mathrm{St}-1}\right) /\left(\mathrm{k}^{\mathrm{St}}-1\right) \text { and } \mathrm{ast}=(\mathrm{k}-1) /\left(\mathrm{k}^{\mathrm{St}}-1\right)
$$

Then:

$$
\begin{aligned}
& \partial \mathrm{a}_{1} / \partial \mathrm{S}_{\mathrm{t}}=-(\mathrm{k}-1) \cdot \mathrm{k}^{\mathrm{St}-1} \cdot \ln (\mathrm{k}) /\left(\mathrm{k}^{\mathrm{St}}-1\right)^{2} \\
& \partial \mathrm{ast}_{\mathrm{t}} / \partial \mathrm{S}_{\mathrm{t}}=-(\mathrm{k}-1) \cdot \mathrm{k}^{\mathrm{St}} \cdot \ln (\mathrm{k}) /\left(\mathrm{k}^{\mathrm{St}}-1\right)^{2}
\end{aligned}
$$

and 


$$
\begin{aligned}
& \partial \ln \left(a_{1}\right) / \partial S_{t}=\left(1 / a_{1}\right) \cdot \partial a_{1} / \partial S_{t}=-\ln (k) /\left(k^{S t}-1\right) \\
& \partial \ln \left(a_{S t}\right) / \partial S_{t}=\left(1 / a_{S t}\right) \cdot \partial a_{t} / \partial S_{t}=-k^{S t} \cdot \ln (k) /\left(k^{S t}-1\right)
\end{aligned}
$$

Thus:

$$
\partial \ln \left(a_{S t}\right) / \partial S_{t}=k^{S t} \cdot \partial \ln \left(a_{1}\right) / \partial S t
$$

As soon as $k>1, k^{\text {St }}$ rapidly exceeds unity, considering usual values of species richness $S_{t}$. It follows that $\ln ($ ast $)$ decreases much faster with species richness than does $\ln \left(a_{1}\right)$. In practice, as soon as $k>$ $1.07, \ln \left(a_{1}\right)$ remains substantially constant while $\ln \left(\mathrm{ast}_{\mathrm{st}}\right)$ steadily decreases rapidly with increasing species richness.

\section{APPENDIX 2}

\section{Derivation of the expression of the abundance unevenness $U^{\prime}\left(S_{t}\right)$ of the broken-stick distribution}

Following MACARTHUR [53] the relative abundance $a^{\prime} i$ of the species of rank ' $i$ ' in the broken-stick distribution of species abundances is given by:

$$
a_{i}^{\prime}=\left(1 / S_{t}\right) \sum_{n=i} \text { to St }(1 / n)
$$

the summation on $(1 / n)$ being extended from $n=i$ to $n=S_{t}$.

In particular:

$$
\begin{aligned}
& a^{\prime} 1=\left(1 / S_{t}\right) \Sigma_{n=1} \text { to St }(1 / n) \\
& a^{\prime} \mathrm{St}^{\prime}=\left(1 / \mathrm{S}_{\mathrm{t}}\right) \Sigma_{\mathrm{n}=\mathrm{St} \text { to St }}(1 / \mathrm{n})=1 / \mathrm{St}^{2}
\end{aligned}
$$

Besides, the direct derivation of the expression of $U^{\prime}\left(S_{t}\right)$ proceeds from reference [9] by MAY. In the "Table 3" of this reference, MAY defines the dominance, ' $d$ ', in the broken-stick distribution as $d=$ $\ln \left(S_{t}\right) / S_{t}$ (at least for $S_{t}$ not too low, say > 10). As the dominance is defined as the higher relative abundance, namely a' 1 in the broken-stick, it comes:

$$
a^{\prime}{ }_{1}=\ln \left(S_{t}\right) / S_{t}
$$

Then, 'J', the inverse of the lowest relative abundance a'st (his equations (1.1) in reference [9]) is identified to $\mathrm{S}_{\mathrm{t}}{ }^{2}$ (his equation (D.6)), so that:

$$
a^{\prime} \mathrm{St}=1 / \mathrm{St}^{2}
$$

and thus:

$$
a^{\prime}{ }_{1} / a^{\prime}{ }_{S t}=\left[\ln \left(S_{t}\right) / S_{t}\right] /\left(1 / S_{t}{ }^{2}\right)=S_{t} \cdot \ln \left(S_{t}\right)
$$

Accordingly, from the definition of $U^{\prime}\left(S_{t}\right)$ :

$$
U^{\prime}\left(S_{t}\right)=\left(\log _{10}\left(a^{\prime}{ }_{1} / a^{\prime} s_{t}\right)\right) /\left(S_{t}-1\right)
$$

it comes finally:

$$
U^{\prime}\left(S_{t}\right)=\left(\log _{10}\left[S_{t} \cdot \ln \left(S_{t}\right)\right]\right) /\left(S_{t}-1\right)
$$

Alternatively, $U^{\prime}\left(S_{t}\right)$ can be, also, fairly well approximated by a power regression of the type: 


$$
\mathrm{U}^{\prime}\left(\mathrm{S}_{\mathrm{t}}\right) \approx \mathrm{a} \cdot \mathrm{S}_{\mathrm{t}}{ }^{-b}
$$

For example, the following approximation can be considered suitable in the range of species richness $\mathrm{S}_{\mathrm{t}}$ between 10 and 120:

$$
U^{\prime}\left(S_{t}\right) \approx 0.994 S_{t}-0.767 \approx S_{t}-0.767
$$

\section{APPENDIX 3}

Intending to be a pedagogical supplement, Box 1 provides a schematic summary of the link between the niche theory, interspecific competition and the outcome of both, in term of the more or less uneven distribution of species abundances within communities - and, consequently, about how speciesrichness is accommodated, schematically.

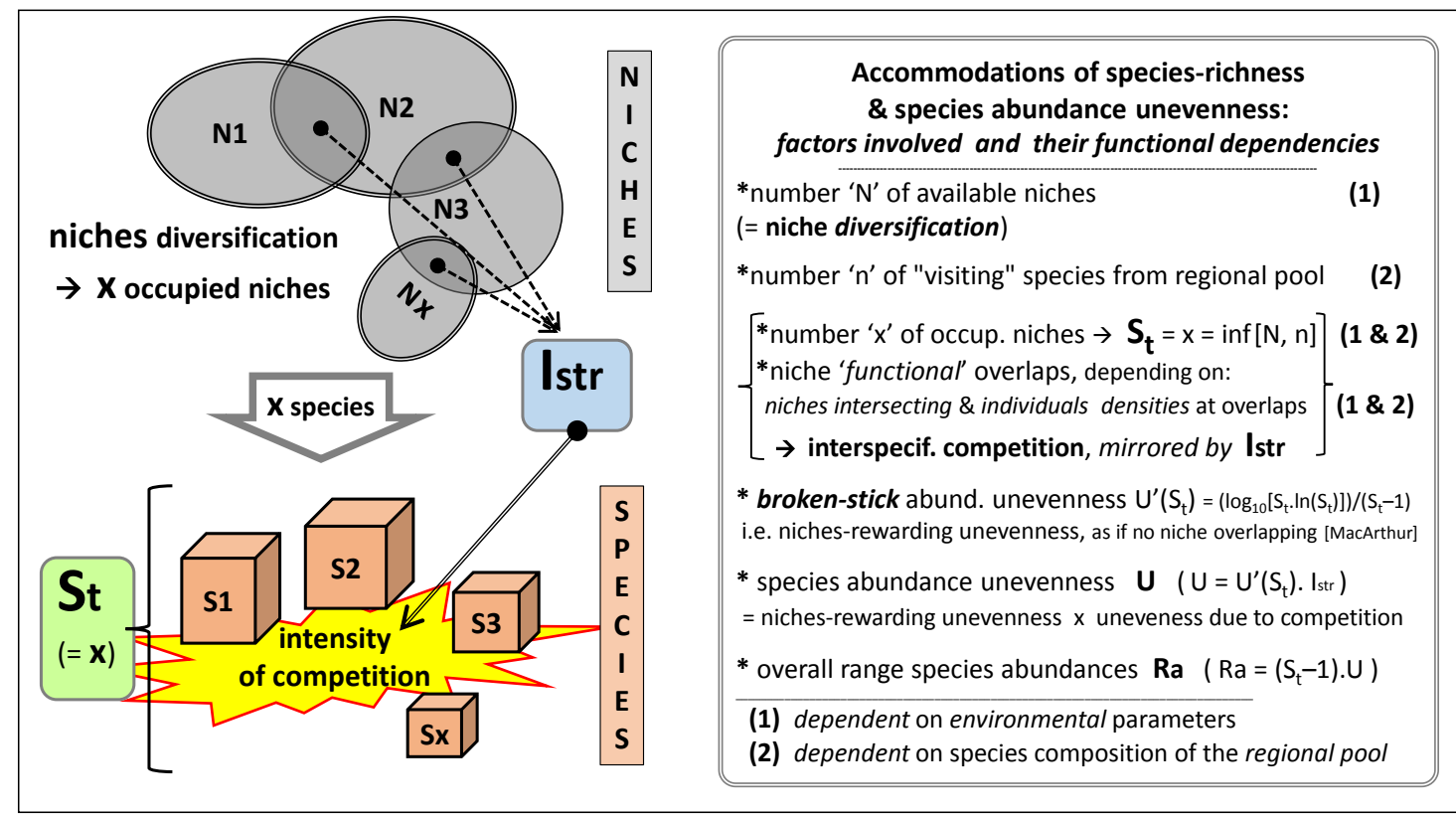

BOX 1 - Schematic representation of how the accommodations of both species-richness and speciesabundance unevenness are partially (i) inter-dependent and (ii) dependent on (ii.a) the environmental parameters and (ii.b) the composition of the regional pool of species. Species richness ' $S$ ' and the standardized unevenness 'Istr' are the two main (and mutually independent) descriptive and functional factors which, by themselves alone, suffice to characterize important quantitative aspects which highlight how proceeds the internal organization of species within communities. Two additional, subordinate factors, the crude abundance unevenness $U$ and the overall range of species abundances $\mathrm{R}_{\mathrm{a}}$ are, for their own, entirely dependent upon the formers, $\mathrm{S}_{t}$ and $\mathrm{I}_{\text {str }}$. The broken-stick abundance unevenness $U^{\prime}\left(S_{t}\right)$ - due to its meaningful linkage with the "non-overlapping niches display" [53] - thereby plays the role of a sort of "compass" supporting the relevant functional interpretation of the "hierarchical" organization among co-occurring species within community.

\section{APPENDIX 4}

\section{The broken-stick distribution, relevantly considered as an 'asymptotic member' of the log- normal family}

One point may deserve further discussion, regarding the status of the "broken-stick" distribution among the wide catalogue of species abundance models (reviewed in [94]). The "broken-stick" 
distribution itself belongs, as the "log-normal" model, to the subset of stochastically generated models. Within this subset, the "log-normal" has now gain large admittance. And this despite the alternative "log-series" model had been advocated still recently as having equal or even a better goodness of fit than the "log-normal" model [95]. Yet, there is now sufficiently increasing evidence that the apparent success of the "log-series" model likely results from (and is therefore restricted to) its applications to substantially incomplete Species Abundance Distributions ("S.A.D.s"), themselves resulting from substantially incomplete samplings [54, 89-92]. Such incomplete samplings being most common in practice, as already underlined in the Introduction. The resulting, incomplete, "S.A.D.s" - therefore more or less truncated towards the rarer species - may thus seem to comply with "log-series" while, in fact, they truly are "log-normal" distributions but artificially truncated towards rarer species, due to sampling incompleteness. Appropriate numerical extrapolations of incomplete samplings additionally support also this interpretation [42-52]. So that, complying with references [54, 89-92, 96], it can be considered that "S.A.D.s" - at least most of them - are better fitted by "log-normal"- like models.

It may thus seem rather surprising that the "broken-stick" distribution plays such a focal role in community ecology, as highlighted above.

In fact, the "broken-stick" distribution is asymptotically close to the family of "log-normal" distributions. This, indeed, is logically related to the stochastic character of the "broken-stick" procedure of niches' apportionment to co-occurring species. This procedure being, in fact, quite close to the stochastic conception of the "log-normal" distribution, apart from the marginal difference that the number of stochastic events involved in the "broken-stick" process is fewer than is the virtual infinity of stochastic events ideally involved in the "log-normal" process. But, in practice, as the convergence is rapid, the "broken-stick" distribution merges fairly well into the "log-normal" family. This may be easily verified empirically, at least for species richness greater than $\approx 10$. Fig. 12 provides an illustrative example for $\mathrm{S}_{\mathrm{t}}=60$.

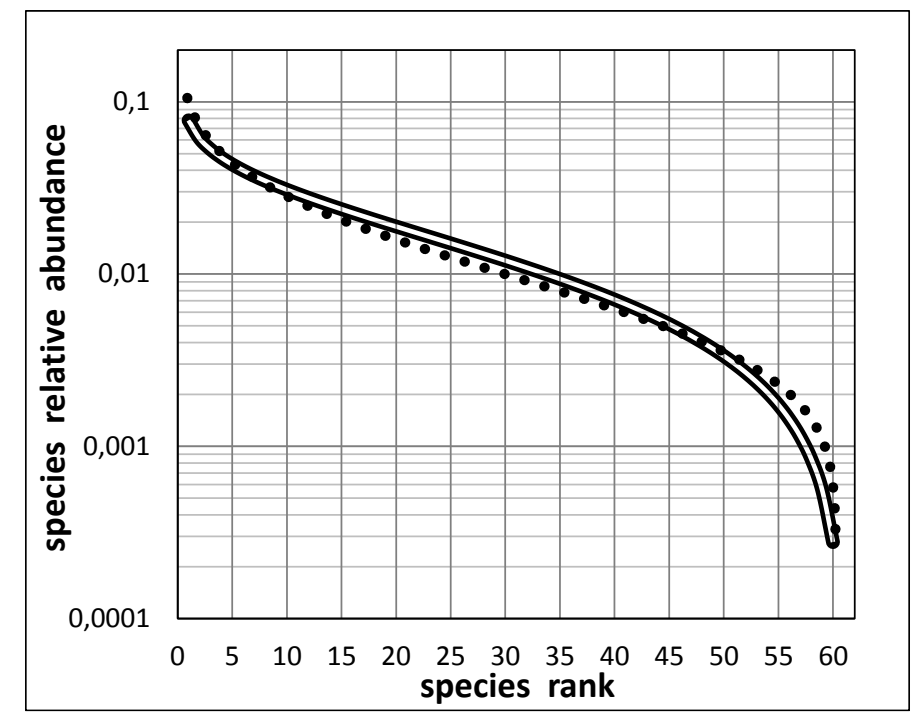

Fig. 12. The "broken-stick" distribution (here for species-richness $S_{t}=60$ : double line) fits reasonably well the log-normal distribution corresponding to the same species-richness and computed with an appropriate standard deviation, here $=0.46$ (dotted curve).

(c) 2021 Béguinot; This is an Open Access article distributed under the terms of the Creative Commons Attribution License (http://creativecommons.org/licenses/by/4.0), which permits unrestricted use, distribution, and reproduction in any medium, provided the original work is properly cited.

Peer-review history:

The peer review history for this paper can be accessed here: http://www.sdiarticle4.com/review-history/67322 